archives-ouvertes

\title{
Fault Zone Imaging from Correlations of Aftershock Waveforms
}

\author{
Gregor Hillers, Michel Campillo
}

\section{To cite this version:}

Gregor Hillers, Michel Campillo. Fault Zone Imaging from Correlations of Aftershock Waveforms. Pure and Applied Geophysics, Springer Verlag, 2018, 175 (8), pp.2643-2667. 10.1007/s00024-0181836-7 . hal-02927974

\section{HAL Id: hal-02927974 https://hal.univ-grenoble-alpes.fr/hal-02927974}

Submitted on 2 Sep 2020

HAL is a multi-disciplinary open access archive for the deposit and dissemination of scientific research documents, whether they are published or not. The documents may come from teaching and research institutions in France or abroad, or from public or private research centers.
L'archive ouverte pluridisciplinaire HAL, est destinée au dépôt et à la diffusion de documents scientifiques de niveau recherche, publiés ou non, émanant des établissements d'enseignement et de recherche français ou étrangers, des laboratoires publics ou privés. 


\title{
Fault Zone Imaging from Correlations of Aftershock Waveforms
}

\author{
Gregor Hillers $^{1,2}$ (D) and Michel Campillo ${ }^{1,3}$
}

\begin{abstract}
We image an active fault zone environment using cross correlations of $15415 \mathrm{~s}$ long 1992 Landers earthquake aftershock seismograms recorded along a line array. A group velocity and phase velocity dispersion analysis of the reconstructed Rayleigh waves and Love waves yields shear wave velocity images of the top $100 \mathrm{~m}$ along the $800 \mathrm{~m}$ long array that consists of 22 three component stations. Estimates of the position, width, and seismic velocity of a low-velocity zone are in good agreement with the findings of previous fault zone trapped waves studies. Our preferred solution indicates the zone is offset from the surface break to the east, $100-200 \mathrm{~m}$ wide, and characterized by a $30 \%$ velocity reduction. Imaging in the $2-6 \mathrm{~Hz}$ range resolves further a highvelocity body of similar width to the west of the fault break. Symmetry and shape of zero-lag correlation fields or focal spots indicate a frequency and position dependent wavefield composition. At frequencies greater than $4 \mathrm{~Hz}$ surface wave propagation dominates, whereas at lower frequencies the correlation field also exhibits signatures of body waves that likely interact with the highvelocity zone. The polarization and late arrival times of coherent wavefronts observed above the low-velocity zone indicate reflections associated with velocity contrasts in the fault zone environment. Our study highlights the utility of the high-frequency correlation wavefield obtained from records of local and regional seismicity. The approach does not depend on knowledge of earthquake source parameters, which suggests the method can return images quickly during aftershock campaigns to guide network updates for optimal coverage of interesting geological features.
\end{abstract}

Key words: Fault zones, Imaging, Surface waves, Crosscorrelation, Aftershocks.

\section{Introduction}

Crustal fault zones are important structures in the global tectonic framework because they accommodate a significant portion of the relative plate motion

1 Institut des Sciences de la Terre, Université Grenoble Alpes, Grenoble, France. E-mail: gregor.hillers@helsinki.fi

2 Present Address: Institute of Seismology, University of Helsinki, Helsinki, Finland.

3 CNRS, Paris, France. through earthquakes or aseismic deformation. The fault zone history governs the present day mechanical fault properties which in turn control the spatial and temporal variations of earthquake properties, slip modes, and seismicity and deformation patterns. Imaging the fault zone architecture is, therefore, important for the understanding of fault and rupture behavior, and for the associated hazard and ground motion scenarios. Multi-scale resolution of the hierarchical fault structure requires an array of complementary investigation methods. Geological and paleoseismological mapping, microscopy, laboratory testing of fault zone rocks, air- and spaceborne geodesy, and subsurface imaging using geophysical potential-field methods can all contribute to a comprehensive characterization of structural fault properties. Observational seismology locates hypocenters of earthquakes, tectonic tremor, and lowfrequency earthquakes that can illuminate active fault structure at depth. The mapping of earthquake source parameters yields further insight into the regional deformation or faulting style, the governing stress regime, and fault strength.

Seismological imaging techniques for the study of fault zone environments include regional earthquake travel time and adjoint tomography (Thurber et al. 2006; Hong and Menke 2006; Tape et al. 2009; Allam and Ben-Zion 2012), teleseismic arrival time analysis (Ozakin et al. 2012), and reflection seismics (Rempe et al. 2013). Deterministic signals reconstructed from the ambient seismic field extend the range of observables (Roux 2009; Zigone et al. 2015; Nakata et al. 2015; Fang et al. 2016). While regional tomography resolves the broader velocity structure around a fault, the used wavelengths and the regularization scales in the inversion schemes typically prohibit a high resolution of strong velocity gradients and localized fault interfaces. 
Better constraints on small-scale velocity variations associated with important structural and mechanical units such as fault cores or primary slip surfaces can be obtained from fault zone waves. These included head waves that refract along sharp impedance contrasts and are thus an important indicator of bimaterial interfaces (Ben-Zion et al. 1992; McGuire and Ben-Zion 2005; Allam et al. 2014). The associated fault segments between different materials tend to evolve skewed rupture directivity patterns that lead to asymmetric ground motion distributions (Andrews and Ben-Zion 1997; Kurzon et al. 2014). Trapped or guided fault zone waves propagate along sufficiently continuous low-velocity waveguides that are the seismic signature of fault damage zones ( $\mathrm{Li}$ et al. 1990; Ben-Zion and Aki 1990; Igel et al. 1997; Ben-Zion 1998; Haberland et al. 2003). The extent and degree of damage around active faults control coseismic near-fault yielding, and can thus have a strong effect on the shaking intensity even at relatively large distances from the fault (Ma and Andrews 2010; Gabriel et al. 2013; Roten et al. 2014). Local body wave patterns from fault zone arrays (Yang and Zhu 2010; Yang et al. 2011, 2014) can further constrain average geometrical and mechanical properties of such low-velocity damage zones.

Very dense arrays deployed in faulting areas consisting of many hundreds of stations (Lin et al. 2013; Ben-Zion et al. 2015) naturally increase the resolution of tomographic images. They allow the reconstruction of additional observables including multiple reflected phases, attenuation coefficients, and refocusing phenomena (Hillers et al. 2014; Liu et al. 2015; Hillers and Campillo 2016; Hillers et al. 2016), and underpin the development of new methods for studying the anatomy of complex fault zone wavefields (Roux et al. 2016).

Here we extend the use of earthquake array records for fault zone imaging. We reconstruct deterministic phases from multiple scattered wavefields by cross-correlating complete seismograms (Campillo and Paul 2003; Paul et al. 2005; Roux and Ben-Zion 2014; Chaput et al. 2015; Hillers and Campillo 2016) of aftershocks associated with the $1992 M_{\mathrm{w}} 7.3$ Landers earthquake. The events were recorded by an approximately $800 \mathrm{~m}$ long fault-normal line array consisting of 22 three component sensors. We make a 2D surface wave tomography based on the reconstructed high-frequency $(1-6 \mathrm{~Hz})$ wavefield to image the shear wave velocity distribution in the top $100 \mathrm{~m}$ around the Landers earthquake fault, California. We resolve a 100-200 m wide lowvelocity zone and an adjacent high-velocity body of similar width that does not break the surface. Properties of other features in the cross-correlation wavefield are used as additional indicators of propagation characteristics. The analysis of the zero-lag correlation amplitude distribution-also referred to as focal spot-gives further clues on the variable wavefield constituents along the line. Longitudinally polarized coherent wavefronts that arrive after the direct surface wave in the correlation functions indicate body wave energy that is reflected off impedance contrasts associated with the low-velocity zone. The velocity contrast and the position and width of the imaged low-velocity zone are compatible with estimates from fault zone wave studies using the same data set (Li et al. 1994a, b, 2007; Peng et al. 2003). Considering the different trajectories, sensitivities, and resolution of fault zone waves and the surface waves analyzed here, this general consistency implies that correlation functions obtained from complete seismograms constitute a useful basis for high-frequency imaging.

The paper consists of two main parts. In the next Sect. 2 we describe the data, details of the methodology, and the main results. This part covers the earthquake data set, the construction of the correlation functions, the surface wave group and phase velocity dispersion analysis, the shear wave velocity inversion using a neighborhood algorithm and a linearized inversion, and the focal spot analysis. The second part in Sects. 3 and 4 includes the discussion and interpretation of the results, and refers in more detail to the figures introduced in Sect. 2.

\section{Data and Methods}

\subsection{Data and Basic Features of Cross-correlation Functions}

We process seismograms from 207 aftershocks recorded between 109 and 112 days after the $M_{\mathrm{w}} 7.3$ 

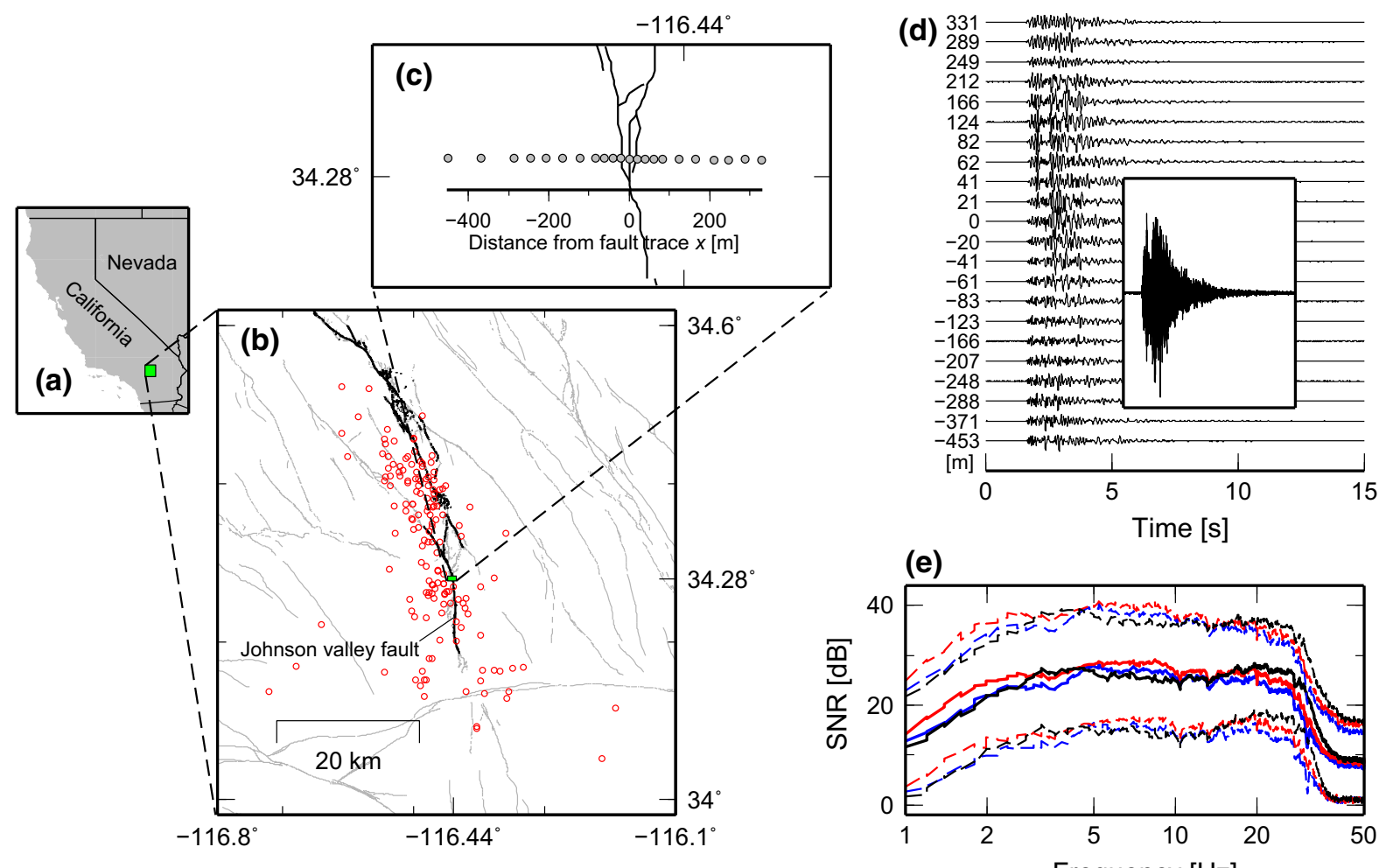

(e)

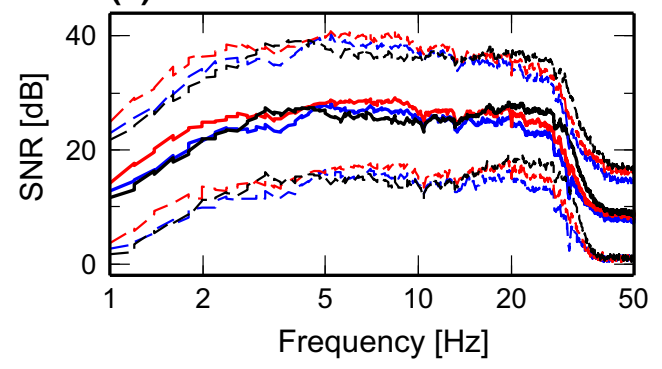

Figure 1

a Location of the study area. b Map of the study area. Red circles indicate the epicenters of the 154 events used in the analysis. Gray lines show mapped fault traces. Black lines indicate the surface rupture of the Landers earthquake. The blowup in $\mathbf{c}$ shows the line array on top of the mapped surface break. d Vertical-component waveforms filtered between 0.5 and $20 \mathrm{~Hz}$. The event occurred four kilometers south of the array in close proximity to the fault. The low-velocity waveguide around $x=100 \mathrm{~m}$ is indicated by the large amplitude wave trains at 3-5 $\mathrm{s}$. The inset shows the $2215 \mathrm{~s}$ long seismograms plotted on top of each other. This representation shows scattered energy exceeds the noise level beyond $15 \mathrm{~s}$. e Signal-to-noise ratio of earthquake signals with respect to pre- $P$ wave arrival noise. Black, red, and blue color are $Z, E$, and $N$ component data, and solid and dashed lines indicate the mean and one standard deviation, respectively

strike-slip Landers earthquake that occurred on 28 June 1992 in the Eastern California shear zone (Fig. 1a, Hauksson et al. 1993; Wald and Heaton 1994). The aftershocks in the magnitude range 0.5 to 3.1 scatter mainly along the north-south trending rupture (Fig. 1b) between the surface and $15 \mathrm{~km}$ depth (Peng et al. 2003). Triggered seismograms were recorded by a line array consisting of $222-\mathrm{Hz}$ three component Sercel L-22 sensors (Fig. 1c). The line was installed along an east-west running road. It crosses the Johnson Valley fault segment about $10 \mathrm{~km}$ to the north of the southern rupture tip and $3 \mathrm{~km}$ to the south of the Kickapoo fault in the stepover between the Johnson Valley and the Homestead Valley segments. The line is $785 \mathrm{~m}$ long and extends from $x=-454 \mathrm{~m}$ to $x=331 \mathrm{~m}$ relative to the rupture surface break at $x=0 \mathrm{~m}$ (Fig. 1c). Nominal inter-station distances along the array vary between 80,40 , and $20 \mathrm{~m}$. The database contains $P$-wave and $S$-wave arrival time information. Waveforms begin generally $10 \mathrm{~s}$ before the $P$-wave onset and the seismogram length varies between 7 and $60 \mathrm{~s}$. The sample rate is $100 \mathrm{~Hz}$. The array-average signal-tonoise ratio of the wave trains (Fig. 1d), where noise is the pre- $P$-wave arrival data, is around $25 \mathrm{~dB}$ in the 2-30 $\mathrm{Hz}$ range (Fig. 1e).

For each event, we cut $15 \mathrm{~s}$ windows from the seismograms recorded at all stations beginning $1 \mathrm{~s}$ before the earliest $P$-wave arrival. Data from 53 events are discarded because of inconsistent record lengths. We whiten the spectra of the windowed seismograms between 0.5 and $20 \mathrm{~Hz}$. The time series are then 1-bit clipped, bandpass filtered again between 0.5 and $20 \mathrm{~Hz}$, and tapered. 1-bit clipping 
(a)

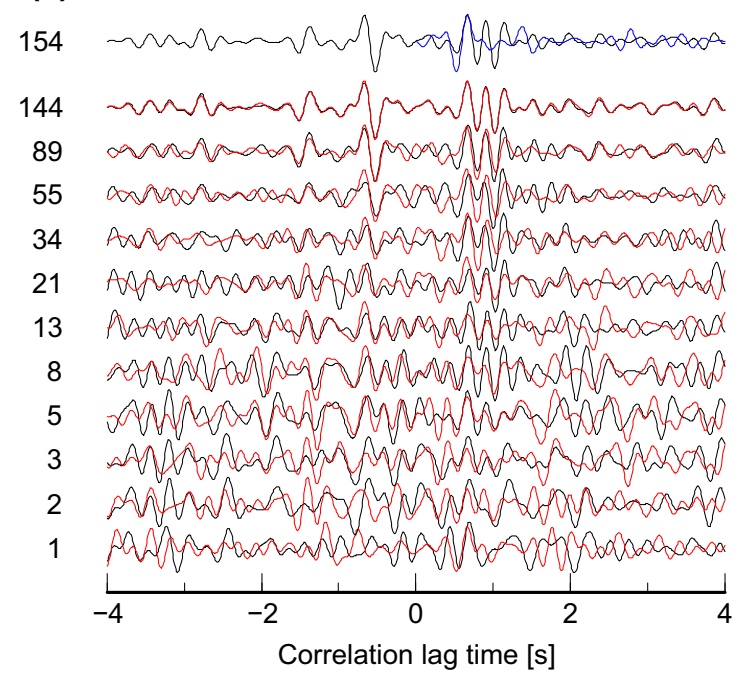

(b)

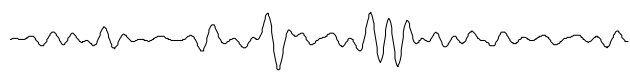

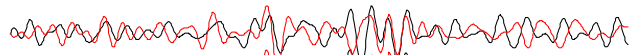

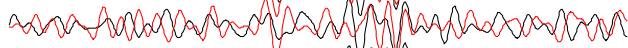

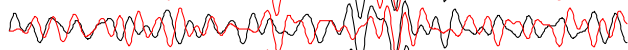

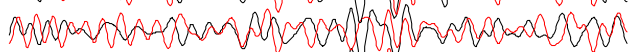

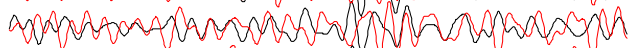

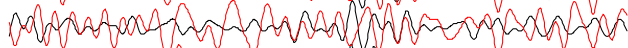

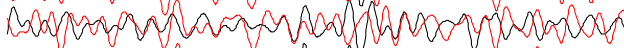

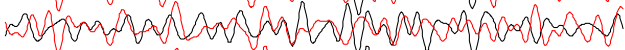

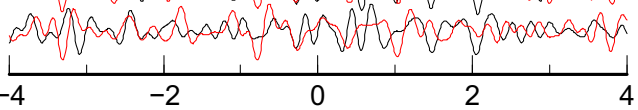
Correlation lag time [s]

(c)
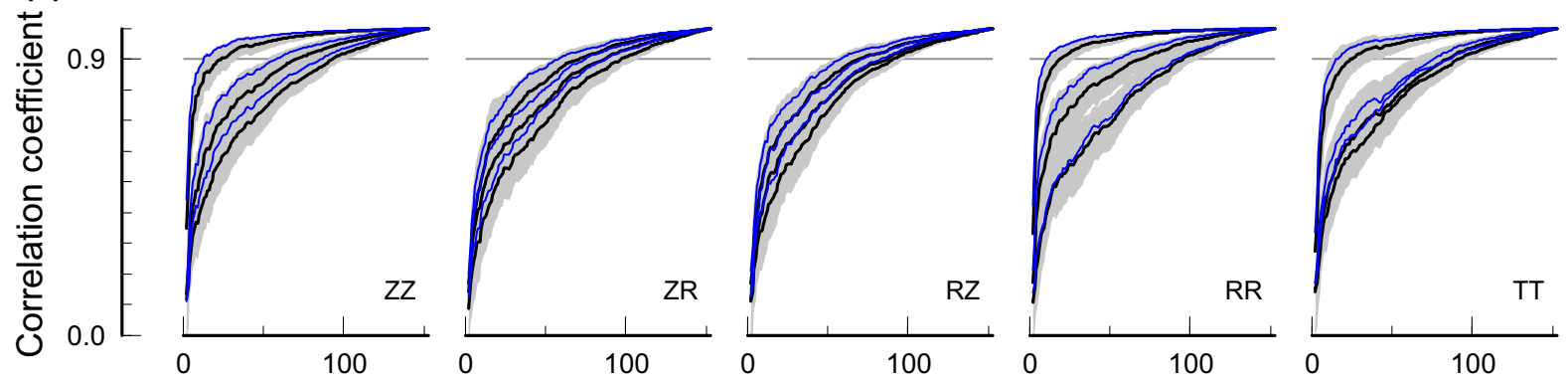

Number of stacked correlation functions

Figure 2

a Convergence of the ZZ cross-correlation (1.5-6 Hz) between stations located at $x=-289 \mathrm{~m}, x=124 \mathrm{~m}$. The numbers on the left indicate the number of correlations that contribute to the stack. Black and red data indicate the chronological and the reversed evolution, respectively. The black trace on top is the final stack of 154 correlations. The blue trace is the time-flipped negative part. b Stack evolution considering events occurring to the south (black) or north (red) of the line array. The smaller number of events to the south controls the shown evolution range. $\mathbf{c}$ Evolution of the similarity to the final stack. Black and blue data correspond to waveforms in a $[-4,4] \mathrm{s}$ and $[-2,2] \mathrm{s}$ window, respectively. Gray areas depict one standard deviation. The three populations correspond to three inter-station distance ranges bounded by 100,300 , and $1000 \mathrm{~m}$

is a standard procedure in ambient noise correlation processing to account for amplitude variability in long ground motion records (Campillo and Roux 2015), and is used here to balance the intensity decay in the earthquake coda (Campillo and Paul 2003). Cross-correlations are computed between all stations, and for all combinations of the vertical $(Z), \operatorname{radial}(R)$, and transversal $(T)$ components. The resulting 154 correlation functions associated with each individual aftershock are then stacked for each station pair and component pair. The convergence characteristics depend on distance, component pair, and frequency (Fig. 2). Generally about 100 events have to be stacked for sufficiently converged Green's function estimates.

The correlation wavefields (Fig. 3) exhibit three main features. First, the typical move-out pattern of a propagating Rayleigh wave emerges in the ZZ, ZR (Fig. 3a, c, e, f), RZ, and RR correlations, and the Love wave is reconstructed in the TT correlations (Fig. 3b). The main observations of the fault-normal velocity structure are obtained from these signals by 
(a) $\mathrm{ZZ}$

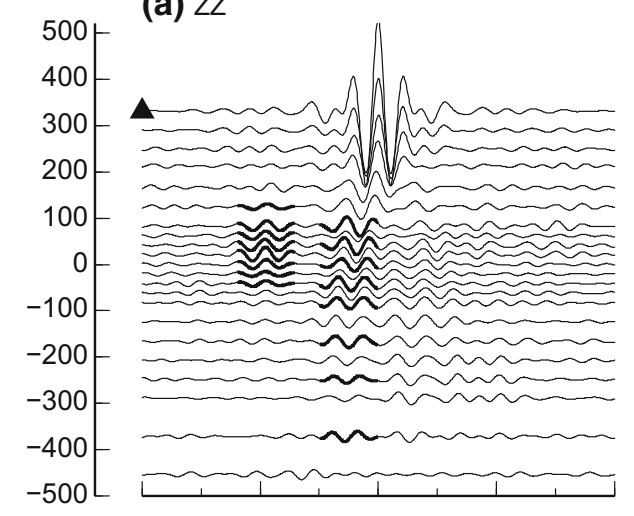

(e) $z Z$

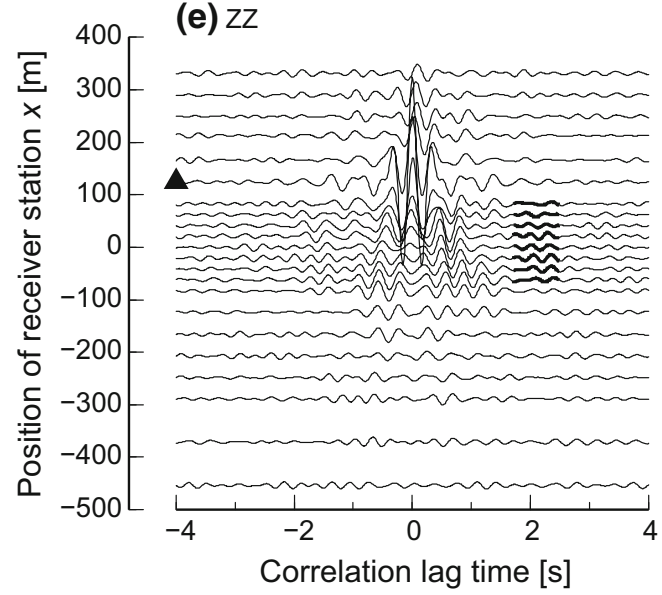

(b) TT

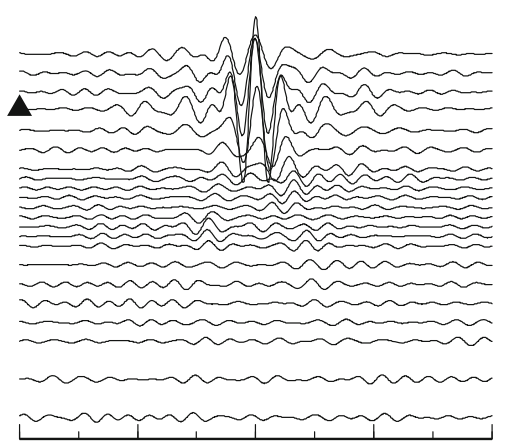

(f) $Z R$

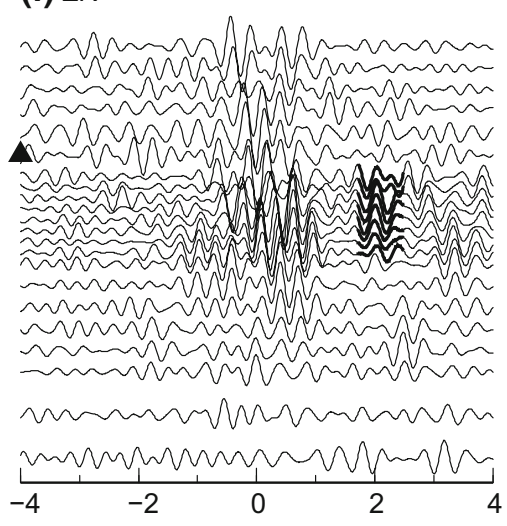

(c)

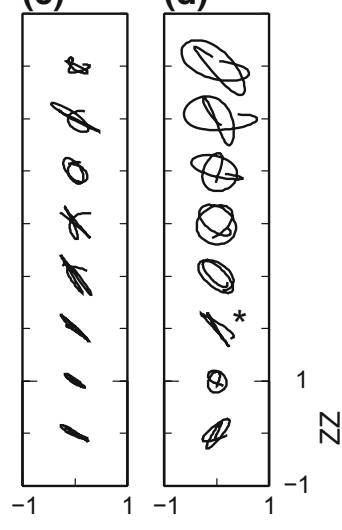

(g)

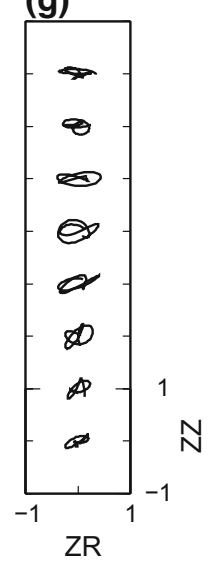

Figure 3

a $\mathrm{ZZ}$ correlation wavefield, $1.5-3 \mathrm{~Hz}$. The triangle indicates the position of the reference station. The highlighted segments are used in the particle motion displays to the right. These waveforms appear at negative and positive lags. We choose to highlight the arrivals on the side with better signal-to-noise ratio. b TT correlation wavefield, 1.5-3 Hz. c Linear particle motion of the reflected wavefronts. These are the highlighted segments around $-2 \mathrm{~s}$ in a. This is reflected energy associated with a virtual source located at $330 \mathrm{~m}$. It arrives after the direct wave at stations located above the low-velocity zone. $\mathbf{d}$ Elliptical particle motion of the direct Rayleigh wave corresponding to the highlighted segments around $-0.5 \mathrm{~s}$ in $\mathbf{a}$. Note the linear polarization of waves around $x=-150 \mathrm{~m}$ indicated by the asterisk. e ZZ and $\mathbf{f} \mathrm{ZR}$ correlation wavefield, 2-4 Hz. g Elliptical particle motion of the reflected wavefronts, corresponding to the highlighted segments around $2 \mathrm{~s}$ in $\mathbf{e}$ and f. The focal spot is the amplitude distribution along zero-lag time. Amplitudes are scaled by the maximum value in each panel. Peak focal spot amplitudes differ for different components (see also Fig. 11)

means of a dispersion analysis of surface wave group velocity, $U$, and phase velocity, $c$ (Figs. 4, 5). Second, the small inter-station distances relative to the wavelength resolve the refocusing - in contrast to the propagating - wavefield. Refocusing results in the large-amplitude focal spot, i.e., the zero-lag correlation amplitude pattern, in Fig. 3a, b, e (Hillers et al. 2014) (the different behavior of the ZR case in Fig. $3 f$ is discussed below). Properties of clean focal spots can be used for inversion-free imaging. Here, however, the limited spatial sampling of the wavefield prohibits wavenumber filtering for accurate surface wave phase velocity estimates (Hillers et al. 2016). Instead, the spatially variable spot symmetry is used as a marker of wavefield properties along the array. The third feature in the correlation wavefields are reflected phases that arrive after the surface waves. Some of these phases are highlighted in Fig. 3a, e, f. A quantitative analysis of these signals is beyond the scope of this work, but basic properties such as their polarization state (Fig. 3c, g) are considered in the discussion of the fault zone environment. 


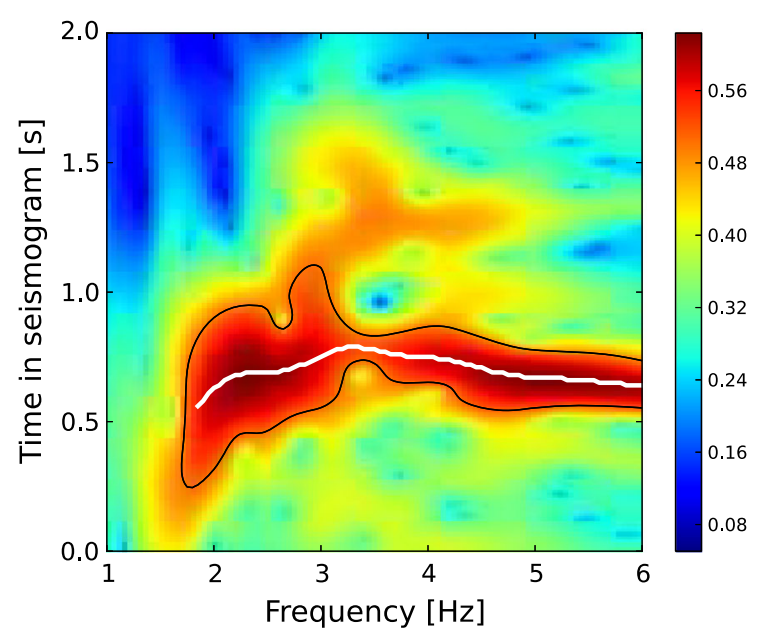

Figure 4

Rayleigh wave group velocity dispersion curve in the timefrequency domain for two stations located at $x=-289 \mathrm{~m}$ and $x=124 \mathrm{~m}$. The colors indicate amplitude after logarithmic stacking of negative-lag and positive-lag ZZ, ZR, RZ, and RR correlation waveforms. The black contour indicates the 0.5 threshold described in the text. The white section of the peakamplitude line indicates data used in the analysis. The $1 \lambda$ distance threshold applies below $1.8 \mathrm{~Hz}$

\subsection{Group Velocity Dispersion Analysis}

The dispersion analysis follows Zigone et al. (2015) who imaged the southern California plate boundary region using surface waves constructed from ambient noise correlations. A frequency-time analysis estimates fundamental mode Rayleigh wave group velocity dispersion curves $U_{R}(f)$ (Fig. 4) between $f=1$ and $6 \mathrm{~Hz}$ in $0.05 \mathrm{~Hz}$ increments from the ZZ, ZR, RZ, and RR correlations. The eight dispersion curves obtained from the four correlations at negative and positive lag times are logarithmically stacked (Campillo et al. 1996). The resulting amplitudes are in the $0-1$ range. We consider only curve segments with amplitudes larger than 0.5 , if the corresponding velocities are in the $0.15-2.5 \mathrm{~km} / \mathrm{s}$ range, and at inter-station distances larger than one wavelength, $\lambda$. The velocity limits discard extreme outliers but at the same time safely exceed the values found after the inversion. We use the rather short far field limit definition of one wavelength to increase the range of usable data. We demonstrate below that the obtained results do not change when we adopt a more conservative value. The resulting continuous dispersion curve segments must cover a frequency range of at least $1 \mathrm{~Hz}$.

To estimate inter-station group velocities $\boldsymbol{m}$ from the travel time data $\boldsymbol{d}$, we use a linearized, damped least squares inversion approach (Tarantola and

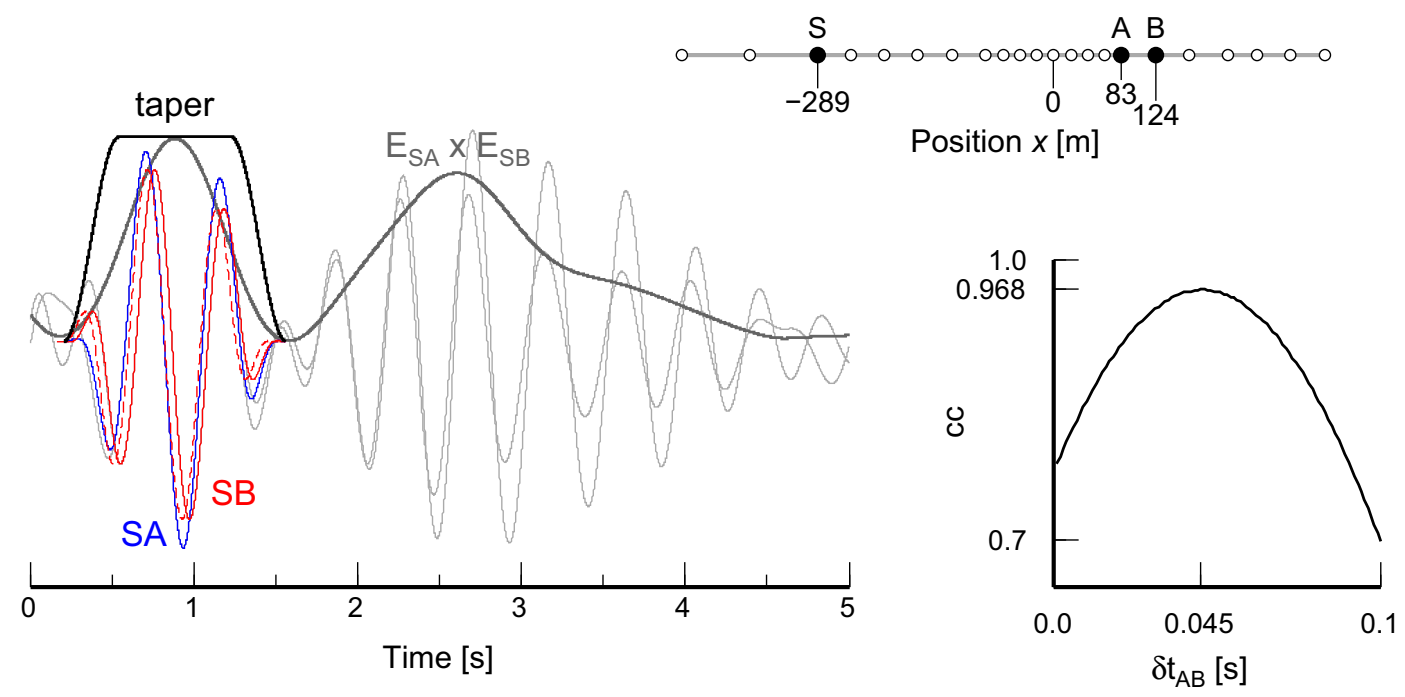

Figure 5

Illustration of the phase velocity measurement. SA and SB are the cross-correlation functions between the source station S and two neighboring stations A and B. The waveforms are positive-lag RR correlations, Gaussian filtered around the central frequency $f_{c}=2.2 \mathrm{~Hz}$. Blue and red lines highlight the windowed and tapered sections of the grey waveforms. The dark grey line is the product of the two function envelopes. The taper has a width of $3 / f_{c}$ and is centered on the peak of the envelope product. The dashed red waveform is shifted relative to the original solid red waveform by $\delta t_{A B}=0.045 \mathrm{~s}$, the travel time difference between A and B estimated with the correlation coefficient $c c$ 


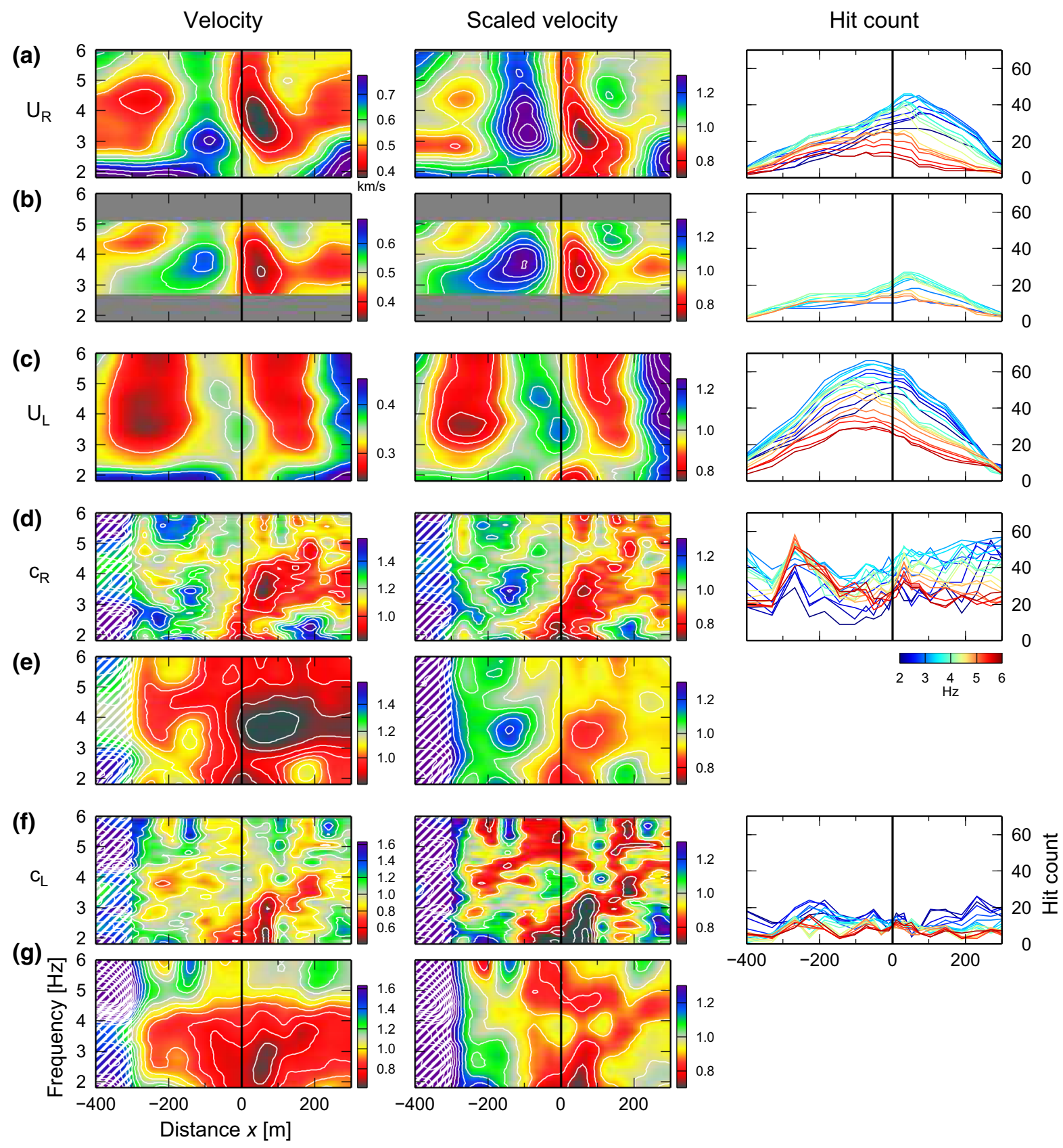

Figure 6

Rayleigh wave and Love wave group velocity dispersion curves $U_{R}(x, f)(\mathbf{a}, \mathbf{b}), U_{L}(x, f)(\mathbf{c})$. The left column shows absolute values. Data in the central column are scaled by the mean value at each frequency. The vertical black line at $x=0 \mathrm{~m}$ indicates the position of the surface break (Fig. 1c). Rayleigh wave and Love wave phase velocity dispersion curves $c_{R}(x, f)(\mathbf{d}, \mathbf{e}), c_{L}(x, f)(\mathbf{f}, \mathbf{g})$. The hatched zones indicate results based on poor data quality. The hit count data in in the right column are associated with different frequencies

Valette 1982) for the solution of $\boldsymbol{d}=\boldsymbol{G m}$, where the matrix $\boldsymbol{G}$ contains the inter-station distances. The solution depends on the model covariance matrix that is governed by some correlation length $\Lambda$ and the model variance $\sigma$. There is significant trade-off among these parameters due to the nonuniform inter-station distances and the strong lateral velocity variations. The chosen values of $\Lambda$ and $\sigma$ lead to a 
favorite $U_{R}(x, f)$ model (Fig. 6a) that exhibits the essential features found in the many models obtained by combining a wide range of $\Lambda$ and $\sigma$ values. This 'steering' is also supported by reproducing the very same key structural units in models that are obtained from various database subsets missing any one to five stations. Finally, the results of this expert opinionbased approach are compatible with the findings of a more formal analysis of the misfit reduction based on $L$-curve properties (Hansen 1992).

Quality control measures along the inversion scheme reduce the usable frequency range to $1.8-$ $5.8 \mathrm{~Hz}$. The dispersion curves $U_{R}(f)$ at each of the 21 inter-station midpoints or cells are smoothed with a $0.3 \mathrm{~Hz}$ running average. Last, we interpolate the $U_{R}(x)$ profiles at each frequency along a line with regular $5 \mathrm{~m}$ spacing. The resulting Rayleigh wave group velocity distributions $U_{R}(x, f)$ are shown in Fig. 6a.

We repeated the $U_{R}$ analysis using a $2 \lambda$ far field definition (Fig. 6b). The usable frequency range and the number of estimates per frequency is reduced, but the pattern of the obtained velocity variations is very similar to the adopted $1 \lambda$ threshold. This indicates that the $1 \lambda$-based results are relatively robust and not systematically biased through body wave energy characterized by small wavenumbers.

The same procedure is applied to TT correlations, yielding Love wave group velocity distributions $U_{L}(x, f)$ (Fig. 6c) that are compatible with the Rayleigh wave results in terms of the lateral velocity variations. Note that the cell hit count statistics in Fig. 6a-c associated with the 1D travel time inversion of Rayleigh and Love waves do not account for the factor of four difference in the number of waveforms used for the dispersion curve estimates of the two wave types.

\subsection{Phase Velocity Dispersion Analysis}

Rayleigh wave phase velocities are estimated from ZZ, ZR, RZ, and RR correlations between two neighboring stations $\mathrm{A}, \mathrm{B}$ and a third station $\mathrm{S}$, respectively (Fig. 5). The algorithm identifies coherent phases in SA and SB correlation functions that are narrow-band filtered using the same Gaussian filter as in the frequency-time analysis. The relevant segments are cut out and tapered. Cross-correlation determines a time shift $\delta t_{\mathrm{AB}}$ that constitutes the $\mathrm{AB}$ travel time estimate with $1 \mathrm{~ms}$ resolution. The phase velocity estimate for the segment bounded by stations $\mathrm{A}$ and $\mathrm{B}$ is then simply $c_{\mathrm{AB}}=\Delta_{\mathrm{AB}} / \delta t_{\mathrm{AB}}$, with $\Delta_{\mathrm{AB}}$ denoting the $\mathrm{AB}$ inter-station distance. The method constitutes a one-dimensional approximation of the phase front tracking that underpins Helmholtz or Eikonal surface wave tomography (Lin et al. 2009; Lin and Ritzwoller 2011; Mordret et al. 2013). Here, too, the measurement has to be made at an average distance from the virtual source that is larger than one wavelength, $\left\langle\Delta_{\mathrm{SA}}, \Delta_{\mathrm{SB}}\right\rangle>\lambda$, and we also imply an upper bound of $2.5 \mathrm{~km} / \mathrm{s}$ on the phase speed values. Estimates obtained from all third stations $\mathrm{S}$, from the four Rayleigh wave component pairs, and from negative and positive time lags are then averaged after further quality control based on waveform similarity. Smoothing along the frequency dimension and interpolation along the space dimension then yields the $c_{R}(x, f)$ distributions shown in Fig. 6d.

This procedure, too, is applied to the TT correlation wavefield for the analysis of Love wave propagation, $c_{L}(x, f)$ (Fig. 6f). The associated hit count indicates the number of measurements per frequency after the quality control from which the averages have been obtained. Here they do reflect the fewer waveforms used for the Love wave observations compared to Fig. 6d.

The $c_{R, L}(x, f)$ images in Fig. 6d, f contain many small scale features that complicate the following inversion for shear wave velocities. The panels in Fig. 6e, g display the solutions of the $\boldsymbol{d}=\boldsymbol{G m}$ inverse problem for the phase velocity estimates using $\Lambda$ and $\sigma$ values similar to the choices used in the group velocity inversion. They represent low-pass filtered versions of the corresponding above images.

We found a higher susceptibility of the $\delta t$ and hence phase velocity $c_{R, L}(x, f)$ estimates to details of the implementation, compared to the robust frequency-time analysis that underpins the group velocity results $U_{R, L}(x, f)$. In particular, the choice for the upper limit of $c$ and the averaging - arithmetic mean or median-have a significant effect on the resulting values of the speed distribution. This effect is largest in the poorly sampled boundary zone at $x<-300 \mathrm{~m}$, and we hence mask all $c$-based results in that area with a hatched pattern. 


\subsection{Shear Wave Velocity Inversion}

The obtained $U_{R, L}(x, f)$ and $c_{R, L}(x, f)$ data are inverted for depth-dependent shear wave velocity distributions, $v_{S}(x, z)$ (Fig. 7), using the GEOPSY geophysical analysis software (Wathelet et al. 2004; Wathelet 2008). The sampling of the parameter space for the dispersion curve computation for layered media is driven by a neighborhood algorithm (Sambridge 1999). The sampling strategy is a stochastic direct search method. The algorithm uses information of all previously generated models to improve the misfit between the synthetic dispersion curves and the observed $U_{R, L}(f)$ and $c_{R, L}(f)$ data by probing the most promising part of the parameter space. The main parameters in the surface wave inversion are the layer thickness, the body wave velocities, and the density. Importantly, the whole parameter space is sampled, subject to a priori parameter constraints, which avoids the strong dependence of linearized inversions on a good starting model. Seismic attenuation is not considered in the forward computation.

The inversion is run for data from each position $x$ independently. At each $x$, it returns an ensemble of 2500 layered $v_{S}(z)$ models. The misfit of the associated synthetic dispersion curves is defined as $m=1 / n_{f} \sqrt{\sum_{i=0}^{n_{f}}\left(x_{d i}-x_{c i}\right)^{2} / x_{d i}^{2}} \quad$ (Wathelet et al. 2004), where $x_{d i}$ and $x_{c i}$ denote the observed and modeled velocity, respectively, at frequency $f_{i}$, and $n_{f}$ is the number of frequency samples. The misfit is used to rank the models and to assess the resolution power and model variability (Figs. 8, 9). Distributions of $v_{S}$ values along lateral and vertical profiles shown in Fig. 8 indicate how well the shear wave models are constrained by the data.

The images in Fig. 7 show averages of the best $n_{b}=10$ and 500 models that have been resampled along a homogeneous depth profile. Averaging between $n_{b}=10$ and 1000 solutions yields very similar $v_{S}$ images that differ only in detail from the single best model. Choosing a uniform misfit threshold for some best model selection is not advantageous considering the dependence of the misfit distributions on location and data set (Fig. 9).

The parametrization consists of $n_{L}$ layers characterized by constant body wave velocities, density, and Poisson's ratio. We do not constrain the $v_{S}$ distribution, but couple the $P$-wave velocities to $v_{S}$. Note that $n_{L}$ is fixed for a given inversion, but each layer's height is a free variable in the optimization process. We repeated the inversion of Rayleigh wave data using two to five layers over a halfspace. The obtained $v_{S}(x, z)$ distributions are generally very similar in terms of the lateral variability. For a smaller number of layers, $n_{L} \leq 3$, the top $10 \mathrm{~m}$ are less well resolved. The difference in using four or more layers is negligible, and the computation time increases significantly for five or more layers. All $v_{S}(x, z)$ distributions shown are obtained with four layers over a half-space (11 free parameters). Vertical resolution is assessed from the depth dependent variability across some hundred best $v_{S}(z)$ models at a given position $x$ (Wathelet et al. 2004). Figure 8 indicates that the resolution-just as the misfit distribution-varies as a function of position and data set. These distributions imply a generally good resolution for $n_{L} \geq 4$ in the top $100 \mathrm{~m}$.

We permit positive and negative $v_{S}$ gradients across layer boundaries, allowing thus for low-velocity layers. The single best models with low-velocity layers tend to have a slightly better misfit compared to the associated positive gradient-only models, but the difference between averages over 10 or 500 best models from each population is insignificant.

The $v_{S}(x, z)$ models can be estimated from separate inversions of the group velocity and phase velocity dispersion curves or from a joint inversion of the two data sets. We discuss results from separate inversions of $U_{R}$ (Fig. 7a, b), $U_{L}$ (Fig. 7d, e), and $c_{R}$ (Fig. $7 \mathrm{~g}, \mathrm{~h}$ ) data. Separate inversion of $c_{L}$ data leads to unstable solutions, which we attribute to the poor quality of the Love wave phase velocity estimates (Fig. 6f). A joint inversion of $U_{R}$ and $c_{R}$ data is also unstable. Instead of tuning this approach by experimenting with different weights we prefer to compare the results from the two separate inversions.

As an additional consistency check we use an average of the ten best-fitting $v_{S}(z)$ models returned by the neighborhood algorithm as the starting model in a linearized damped least-squares inversion of the $U_{R}(f), U_{L}(f)$, and $c_{R}(f)$ dispersion data (Herrmann 2006) using $5 \mathrm{~m}$ vertical sampling. The solutions after five iterations (Fig. 7c, f, i) are overall compatible with the images based on the stochastic 

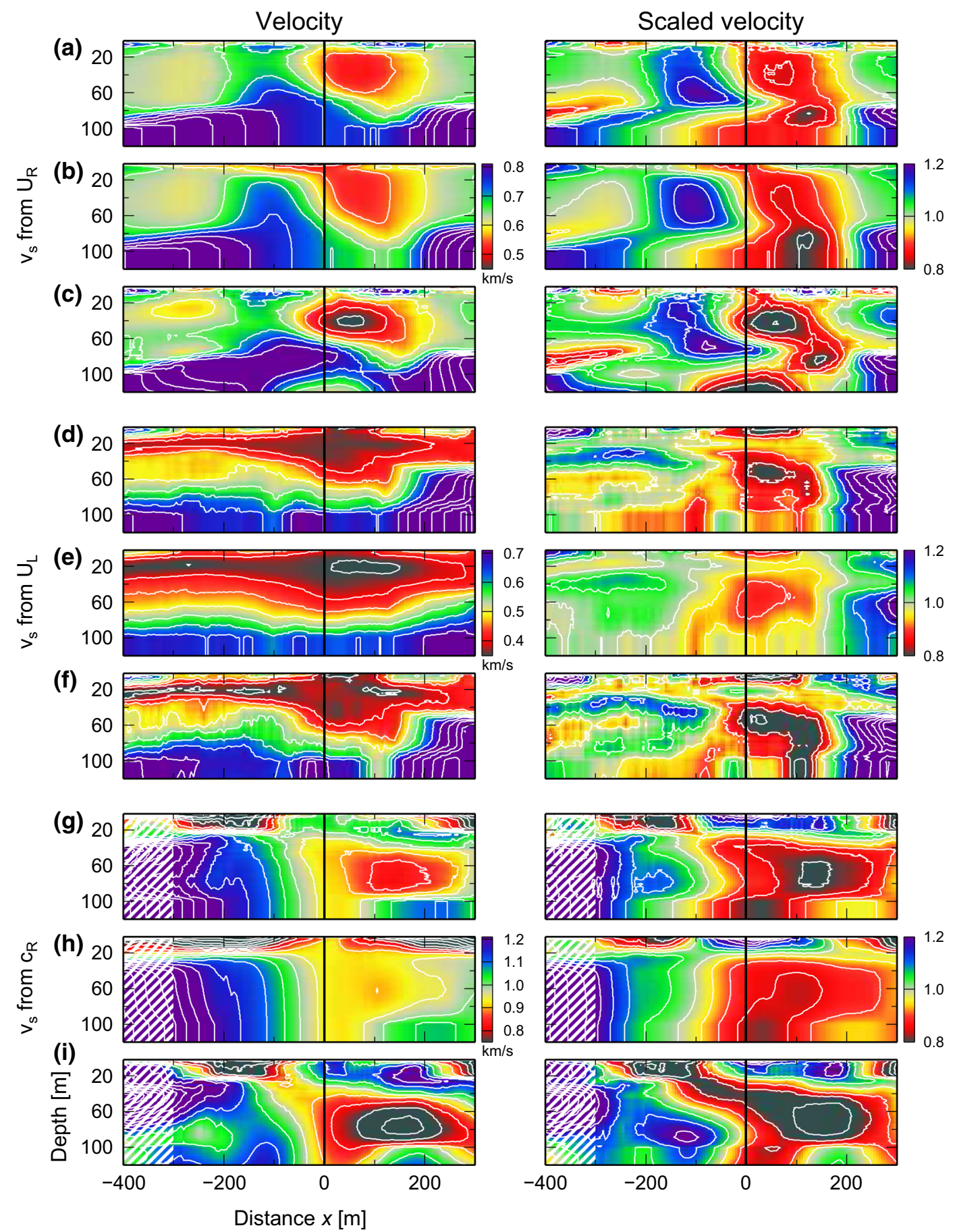

Figure 7

Shear wave velocity distributions obtained from the inversion of Rayleigh wave group velocity (a-c), Love wave group velocity (d-f), and Rayleigh wave phase velocity dispersion (g-i). The hatched zones indicate results based on poor data quality. The left column shows absolute velocity values. Data in the right column are scaled by the mean value at each depth. Images in $\mathbf{a}, \mathbf{d}, \mathbf{g}$ are averages of the 10 best models obtained with the neighborhood algorithm. Images in $\mathbf{b}, \mathbf{e}, \mathbf{h}$ are averages of the 500 best models obtained with the neighborhood algorithm. Images in $\mathbf{c}, \mathbf{f}, \mathbf{i}$ are solutions obtained with the linearized inversion. The vertical black line at $x=0 \mathrm{~m}$ indicates the position of the fault surface break (Fig. 1c). The vertical white contours at the base of the neighborhood algorithm results indicate the halfspace 
(a)

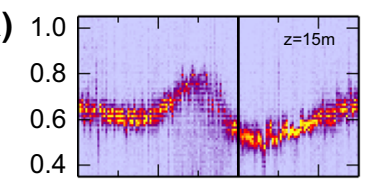

(b)

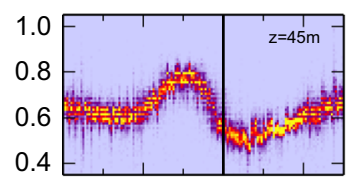

(c)

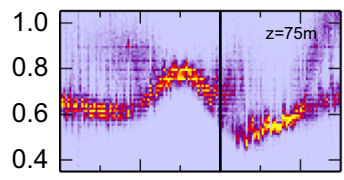

(d)

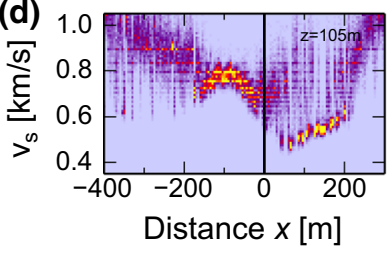

$v_{s}$ from $U_{R}$
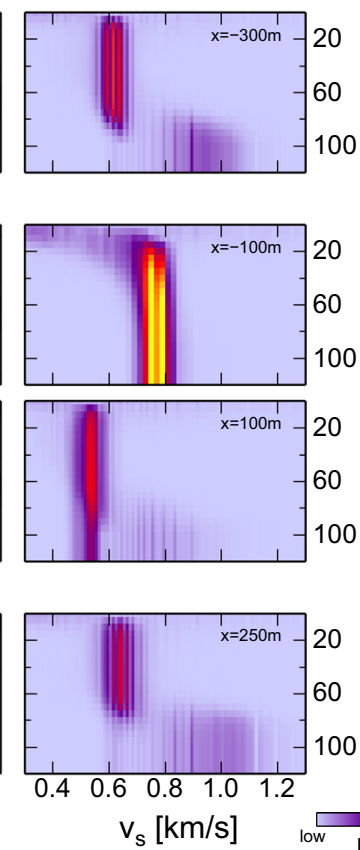

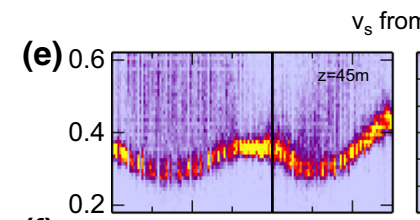

(f)
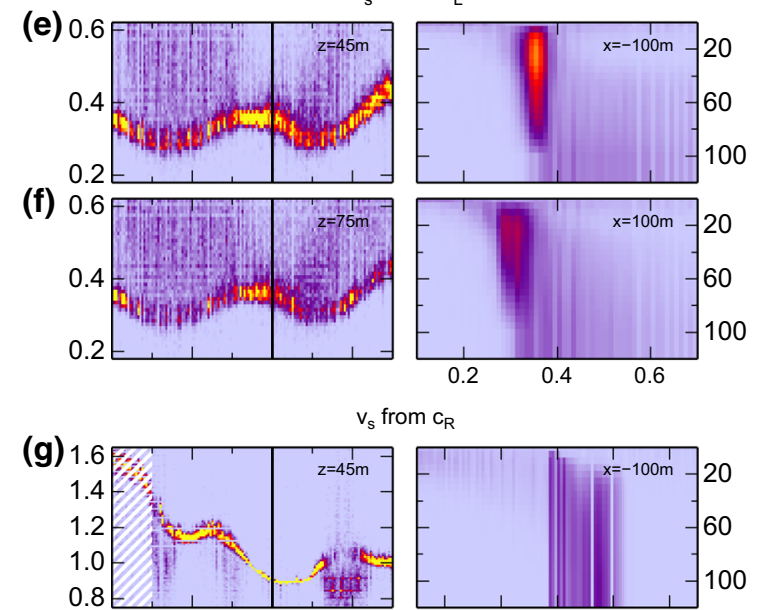

(h) 1.6
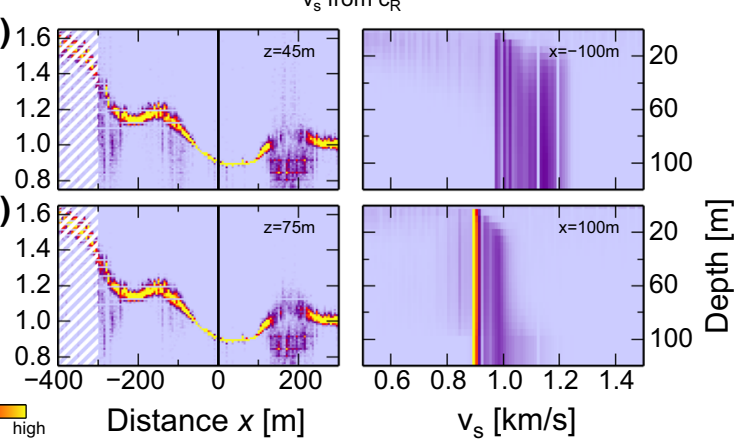

Figure 8

Distributions of shear wave velocity values from the 500 best-fitting $v_{S}(z)$ models obtained with the neighborhood algorithm at each position $x$. For each of the three $U_{R}(\mathbf{a}-\mathbf{d}), U_{L}(\mathbf{e}, \mathbf{f})$, and $c_{R}(\mathbf{g}, \mathbf{h})$ cases the images in the left column show along-line $v_{S}$ distributions from a narrow range around depth $z$ indicated in the upper right. Images in the corresponding right column show depth distributions of $v_{S}$ obtained in a narrow interval around different positions $x$ indicated in the upper right. Hot colored high densities indicate well-constrained values. The hatched zones indicate results based on poor data quality

inversion, but tend to enhance vertical velocity variations at a given position. The associated sensitivity kernels (Fig. 10) highlight the variable resolution power of the $U_{R}, U_{L}$, and $c_{R}$ data. These frequency dependent kernels suggest that the $U_{R}$ data best constrain the $v_{S}$ models over the $100 \mathrm{~m}$ depth range. The most complete lateral and vertical sensitivity controls also the relatively homogeneous model variability (Fig. 8a-c). In contrast, the Rayleigh wave phase velocity estimates have the overall lowest sensitivity to perturbations in the $v_{S}$ model. Considering further the data quality and synthetic dispersion characteristics (Fig. 9) we rate the $U_{R}$-based $v_{S}$ distributions most significant, followed by the $U_{L^{-}}$ and $c_{R}$-based results.

\subsection{Focal Spot Analysis}

We now focus on the correlation wavefield at subwavelength distances. For the same source and receiver orientation (ZZ, RR, TT) the spatial amplitude field at zero correlation lag time is characterized by large values around the origin (Fig. 3). This feature is referred to as the focal spot (Catheline et al. 2008; Gallot et al. 2011; Hillers et al. 2014). The large amplitude spot is caused by refocused energy of a time reversed converging wavefield that interferes with the diverging wavefield around the origin (e.g., Fink et al. 1989). For single mode isotropic surface wavefields the time domain focal spot is equivalent to the spatial autocorrelation in the spectral domain (Aki 1957). The spot size is controlled by the diffraction limit and hence by local medium properties. Focal spot properties can thus form the basis for local imaging approaches (Catheline et al. 2008; Benech et al. 2009; Hillers et al. 2016).

The ZZ, RR, and TT focal spot shapes of a refocusing Rayleigh wave follow zero-order Bessel functions, $J_{0}$ (Fig. 11a, Haney et al. 2012). This explains the large amplitudes relative to the propagating wave in Fig. 3a, b, e. Note that the RR and TT 

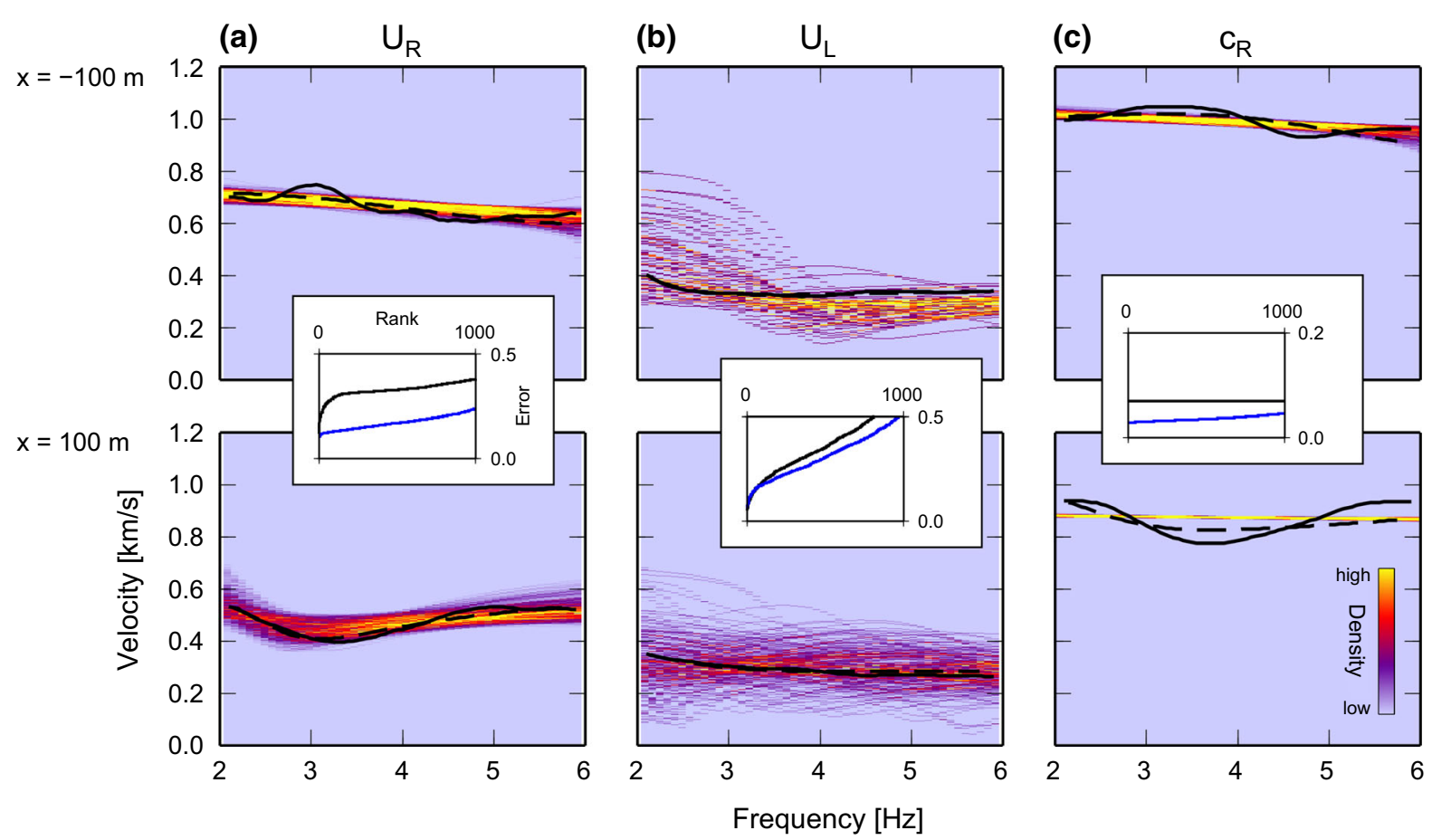

Figure 9

Observed and modeled dispersion curves. The top and bottom row correspond to data at the $x=-100 \mathrm{~m}$ and $x=100 \mathrm{~m}$ positions, respectively. In each panel, color indicates the distribution of velocity values ( $U$ or $c$ ) associated with the 500 best-fitting synthetic dispersion curves obtained with the neighborhood algorithm, the dashed black line is the result of the linearized inversion, and the solid black line is the observed dispersion. The insets show the corresponding misfit distributions, where the blue (black) data correspond to the position at $x=-100 \mathrm{~m}(x=100 \mathrm{~m})$

focal spot shapes are modulated by a $J_{2}$ function (Fig. 11a). For the TT case, the sum $J_{0}+J_{2}$ results in the familiar zero transversal motion of far field Rayleigh waves (Haney et al. 2012) (Properties of $\mathrm{RR}$ and TT Love wave focal spots are discussed in the Results Sect. 3).

In contrast to the maximum ZZ, RR, and TT autocorrelation values the phase difference between the radial and vertical Rayleigh wave motion cancels the mixed-component coherency at the origin (Fig. 11a). As a result, the RZ and ZR focal spot shapes follow a Bessel function of order one, $J_{1}$ (Haney et al. 2012). Because of the zero autocorrelation value the propagating waves in the distant point correlations dominate the pattern in Fig. 3f. In summary, the zero-lag correlation tensor reflects local surface wave properties, and deviations from the theoretical shapes can indicate changes in the propagation regime or wavefield constituents.
The RZ and ZR fields have been argued to provide the most robust information on Rayleigh wave propagation (Haney et al. 2012). Our observed high frequency RZ and ZR zero-lag distributions show autocorrelation values that fluctuate around the expected zero level. The shape is overall consistent with the $J_{1}$ parametrization (Fig. 11c, d). These high frequency data are thus compatible with the refocusing of a wavefield that is dominated by Rayleigh waves.

At lower frequencies we observe spatially dependent variations of this pattern. Importantly, the RZ and ZR distributions associated with reference stations located to the west of the fault above the highvelocity body are characterized by non-zero amplitudes at $r=0 \mathrm{~m}$ (Fig. 11e), which is not compatible with the refocusing of Rayleigh waves. Amplitudes close to unity suggest that linear polarized body waves with in-phase motion on the vertical and fault- 


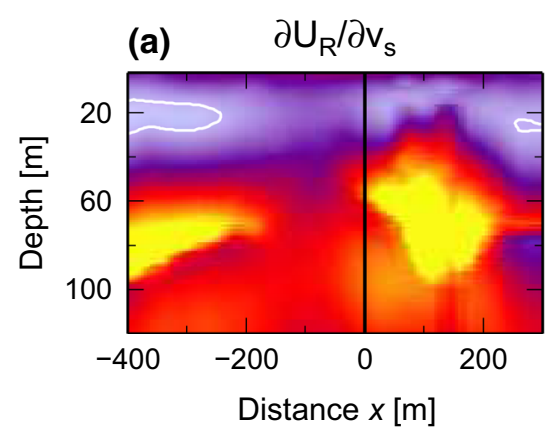

(d)

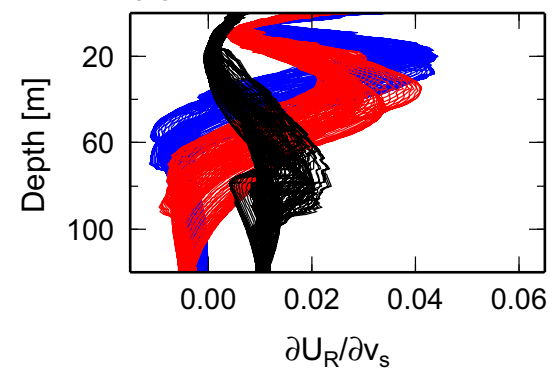

(b)

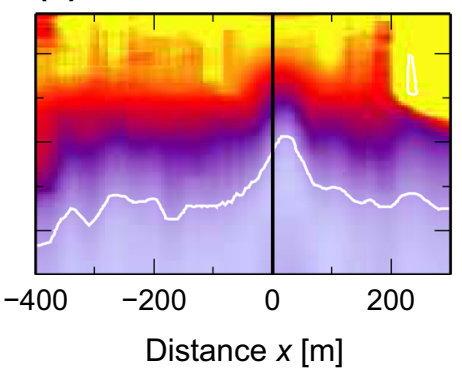

(e)

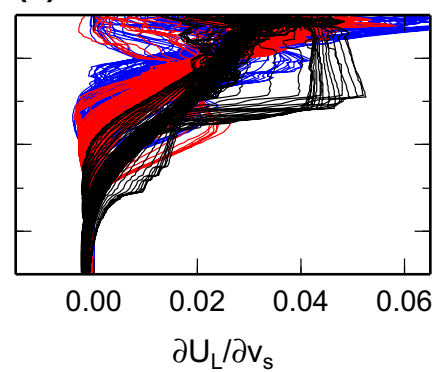

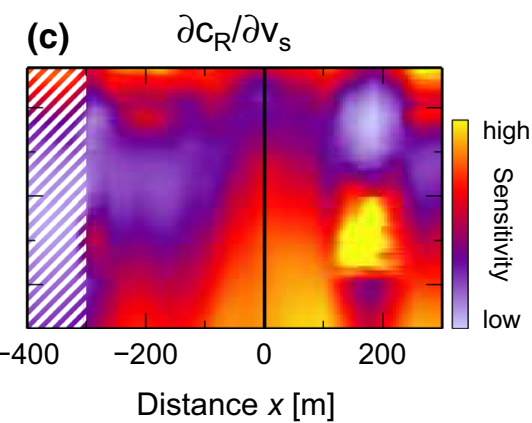

(f)

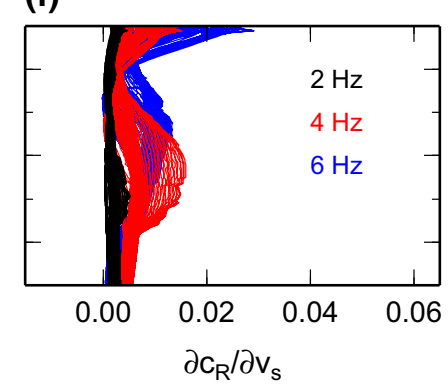

Figure 10

Sensitivity kernels associated with the linearized shear wave velocity inversion from $U_{R}, U_{L}$, and $c_{R}$ data. Panels in the top row (a-c) show spatial distributions of $2 \mathrm{~Hz}$ kernels. The white contour indicates zero. The hatched zones indicate areas with poor data quality. Panels in the bottom row (d-f) show the depth dependence of 2, 4, and $6 \mathrm{~Hz}$ kernels. The $2 \mathrm{~Hz}$ data are the same as in the top row

perpendicular radial components interfere with the Rayleigh waves. We note that a similar observation of intermittent linear polarization in this frequency range and in this area is made for propagating waves. This is indicated in Fig. 3d by the ZR-ZZ particle trajectory that is annotated with the asterisk; we report that this linear polarization is generally observed in this area and not sensitive to the location of the reference station.

Returning to the focal spot properties, Fig. 11e shows further that the shapes of the amplitude distributions vary with the receiver location. The ZR data associated with receiver stations on top of the low-velocity zone (thick red lines) exhibit a shortwavelength pattern. This is superimposed on the long-wavelength $J_{0}$ shape that dominates the other shown amplitude profiles. Results associated with reference stations located to the east of the fault (Fig. 11f) exhibit again a consistent $J_{1}$ shape that is independent on the relative location of the receiver stations.

Together these observations clearly show that the composition of the refocused wavefield depends on location and frequency. The relative contribution of different types of waves to the focal spots varies between locations on top of the low- or high-velocity zone, in particular at lower frequencies around $2.5 \mathrm{~Hz}$. The different wave types and variable polarization states make it difficult to estimate the Bessel functions' first roots as proxies for the surface wavelength and phase velocity (Hillers et al. 2014, 2016). The line geometry prohibits an efficient wavenumber filtering of the reconstructed amplitude profiles for improved estimates (Hillers et al. 2016). Phase velocity distributions $c_{R}(x, f)$ (not shown) obtained from the raw spots are broadly compatible with the tomographic results, but the images are of overall poor quality and hence not further evaluated here.

Instead, we assess the focal spot symmetry (Fig. 12). Similar to the properties of the SPAC imaginary component (Asten 2006) asymmetry is a signature of imperfect azimuthal averaging that can be caused by local scatterers (Hillers et al. 2016). In contrast, symmetric shapes suggest that the correlations and focal spots are constructed from isotropic wavefields (Fig. 12b, c, e, f). We estimate the difference in amplitude values at distances $-r$ and $r$ 


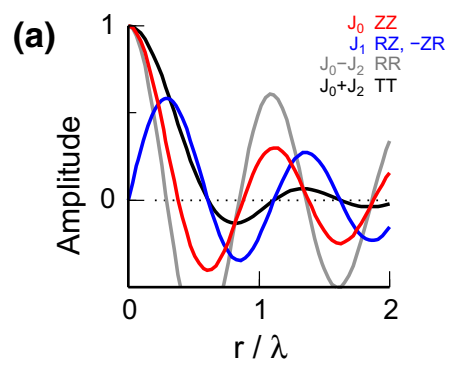

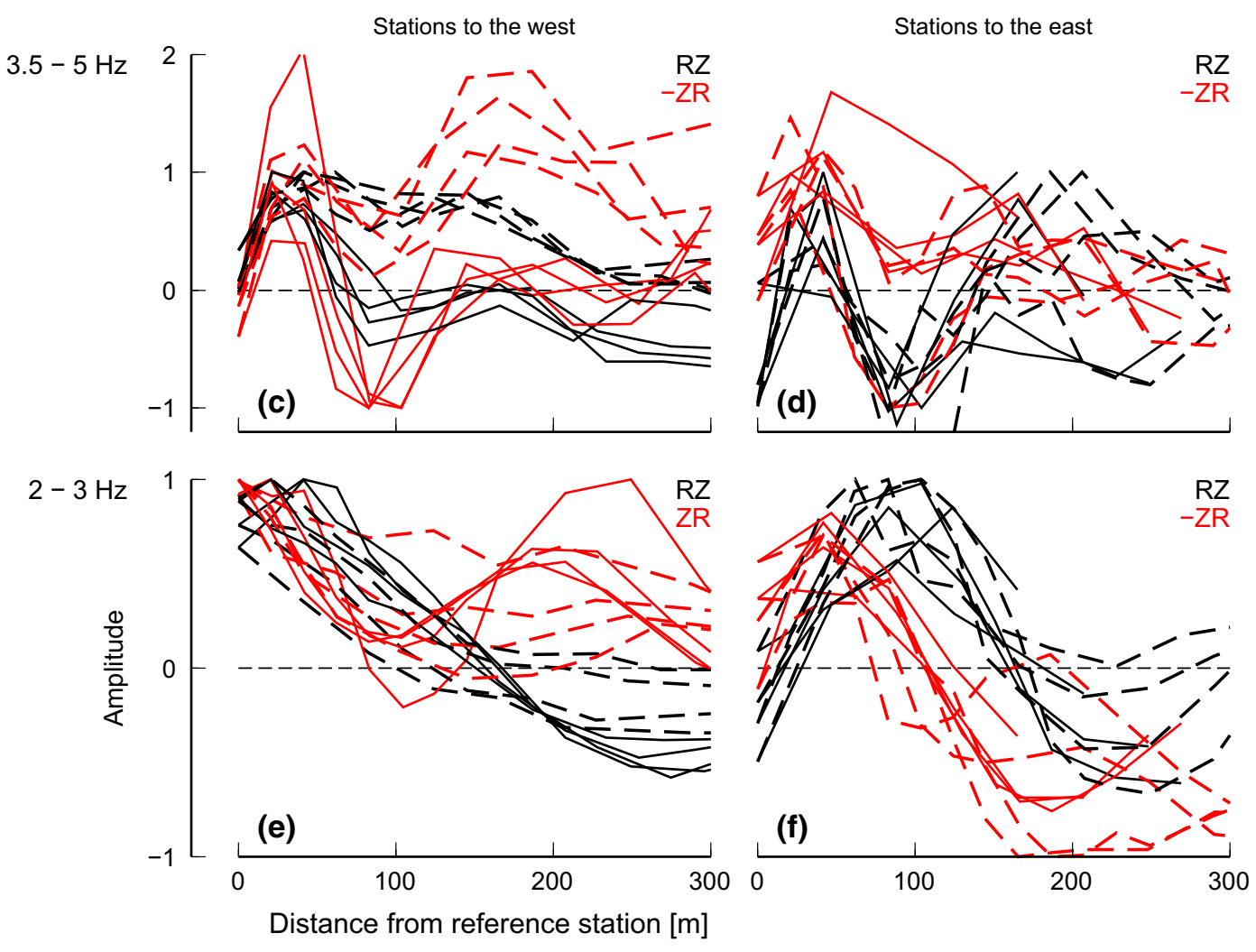

Figure 11

a Theoretical shapes of ZZ, RZ, ZR, RR, and TT Rayleigh wave focal spots (Haney et al. 2012). The argument $\omega r / c_{R}$ of the Bessel functions is implicit. For Love waves, the ZZ, RZ, and ZR coherency is zero, and the plus and minus signs in the RR and TT expressions are exchanged. b Positions of the two times four reference stations used in panels (c-f), which show stacks of one-sided focal spots from RZ and ZR correlations. Solid (dashed) lines indicate data from receiver stations to the east (west) of the reference position. The ZR amplitudes in c, d, and $\mathbf{f}$ are multiplied with -1 to highlight the similarity with the RZ data

around the reference station-which is indicated by the dissimilarity of the black and red lines in Fig. 12a-c-as a function of frequency (Fig. 12df). Here we use ZZ, RR, and TT data interpolated on a regular $20 \mathrm{~m}$ grid. Again, a mismatch between the two lines, such as in Fig. 12a, d around reference position $x=-50 \mathrm{~m}$, is an indicator of directional surface wave propagation or interfering body waves.

\section{Results}

\subsection{Group Velocity and Phase Velocity Dispersion}

The $U_{R}(x, f)$ distribution (Fig. 6a) exhibits two prominent features, the low-velocity zone to the east of the fault trace between $x=0 \mathrm{~m}$ and $x=100 \mathrm{~m}$ and the adjacent high-velocity zone or ridge to the 


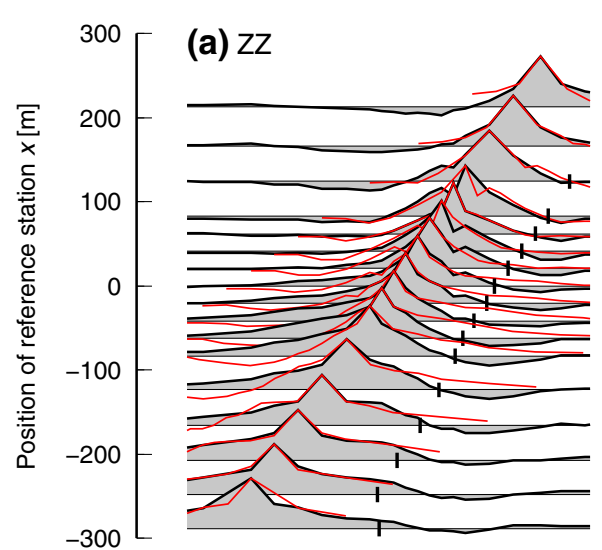

(d)

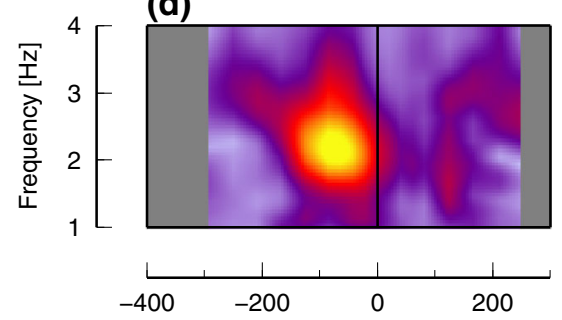

(b) $R R$

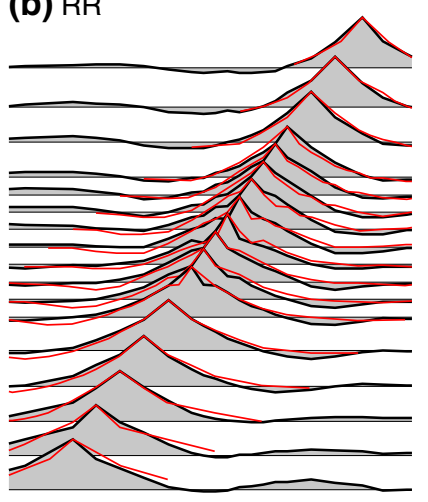

(e)

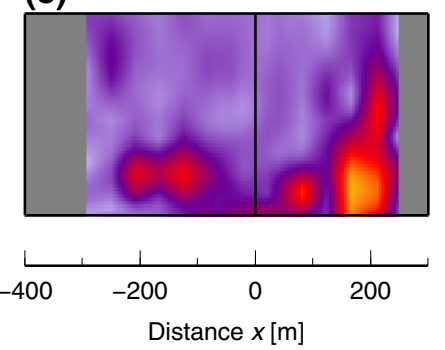

(c) $\mathrm{TT}$

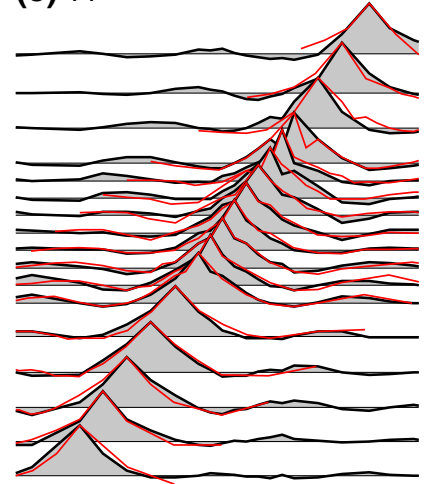

(f)
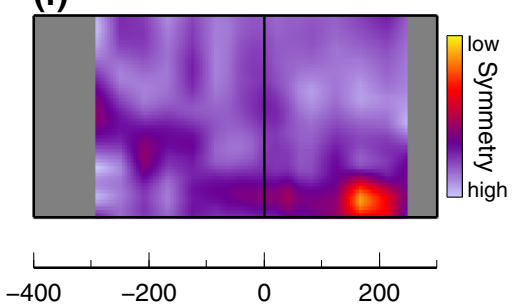

Figure 12

a ZZ, b RR, and c TT zero-lag correlation amplitude distributions or focal spots at $2.5 \mathrm{~Hz}$. Red lines indicate the flipped original black lines. Vertical black stubs indicate the predicted zero crossing positions at $3 \lambda / 8=3 / 8 \cdot c / 2.5 \mathrm{~m}$ from the refocusing points (Hillers et al. 2014), where $c$ are the $2.5 \mathrm{~Hz}$ phase velocity values from Fig. 6d. Panels d-f illustrate the frequency dependent asymmetry-the area enclosed by red and black lines in $\mathbf{a}-\mathbf{c}$ - as a function of the position of the reference station. The location around $x=-100 \mathrm{~m}$ of the high-amplitude feature in $\mathbf{d}$ is compatible with the location of the high-velocity zone in Fig. 6a between 2 and $3 \mathrm{~Hz}$. The above-average asymmetry in $\mathbf{e}$ and $\mathbf{f}$ is also collocated with increased velocities at low frequencies

west between $x=-200 \mathrm{~m}$ and $x=0 \mathrm{~m}$. The wave speeds vary between 400 and $800 \mathrm{~m} / \mathrm{s}$ in these two regions across the $2.5-4.5 \mathrm{~Hz}$ range, resulting in a $50 \%$ peak velocity reduction. High velocity refers to the values that are significantly larger compared to the level at $x<-200 \mathrm{~m}$ and $x>150 \mathrm{~m}$. Values in these boundary regions are less well constrained because of lower path coverage. However, we consider the decrease of velocities away from the ridge towards smaller $x$ robust. This result is reproduced if we select and weight data differently, e.g., if we neglect data from five stations that are collocated with the high-velocity zone in the inversion. The pattern also emerges when we use the $2 \lambda$ threshold (Fig. 6b).

The corresponding Love wave results $U_{L}(x, f)$ shown in Fig. 6c corroborate these findings. The position and thickness of the low- and high-velocity zones are very similar to the Rayleigh wave results. Velocities also decrease towards the western edge of the array, confirming the distinct character of the high-velocity body. Note that the obtained sub1000 m/s Rayleigh wave speeds and yet slower Love wave speeds are compatible with the move out patterns shown in Fig. 3a, b.

In general the same two zones also emerge in the corresponding phase velocity distributions $c_{R, L}(x, f)$ (Fig. 6d-g). The $x$-averaged images (Fig. 6d, f) exhibit variations on scales that are smaller compared to the $U_{R, L}(x, f)$ maps. As said, applying the same lateral inversion smooths these variations (Fig. 6e, g), yielding images with a resolution that is compatible with the group velocity results. The Rayleigh wave phase velocity maps $c_{R}(x, f)$ (Fig. 6d, e) show a 100$200 \mathrm{~m}$ wide low-velocity zone again at frequencies below $5 \mathrm{~Hz}$ centered around $x=50-100 \mathrm{~m}$. The high-velocity region around $x=-150 \mathrm{~m}$ and $3 \mathrm{~Hz}$, best seen in the scaled velocity images, is compatible with the high-velocity body in the corresponding Rayleigh group velocity results in Fig. 6a, b. Typical 
values of the low-velocity zone around $3 \mathrm{~Hz}$ are 700 $800 \mathrm{~m} / \mathrm{s}$, and the velocities to the west of the fault are around $1400 \mathrm{~m} / \mathrm{s}$, supporting the $50 \%$ reduction estimate. The Love wave phase velocity results (Fig. 6f, g) stand out because of the very narrow low-velocity zone at low frequencies at $x=50 \mathrm{~m}$.

For both Rayleigh and Love waves the respective $c$ and $U$ results differ at $x<-300 \mathrm{~m}$. As said, our confidence into the phase velocity estimates in that area is lowest. The relation between $U$ and $c, U=$ $c^{2} /(c-\omega d c / d \omega)$ invites a consistency check by computing $c$-based $U(x, f)$ distributions. Using fairly smoothed phase velocity dispersion curves to avoid problems associated with the $d c / d \omega$ term yields group velocity images (not shown) that agree on the first-order features, but the overall similarity to the measured group velocities is rather limited. These differences help further explain the problems in the joint $v_{S}(z)$ inversion of $c(f)$ and $U(f)$ dispersion data reported in Sect. 2.4.

\subsection{Shear Wave Velocity Distributions}

We compare the shear wave velocity distributions inverted separately from the $U_{R}, U_{L}$, and $c_{R}$ data sets (Figs. 7, 8). The most prominent feature in the Rayleigh wave group velocity-based $v_{S}(x, z)$ distributions (Fig. $7 \mathrm{a}-\mathrm{c}$ ) is the velocity contrast across the fault surface break at $x=0 \mathrm{~m}$, with the high-velocity body to the west and the low-velocity zone to the east. The east-dipping interface around $x=0 \mathrm{~m}$ below $20 \mathrm{~m}$ is driven by the oblique geometry of the low-velocity zone in the corresponding $U_{R}(x, f)$ images. Shear wave velocities at $x=-100 \mathrm{~m}$ and $x=100 \mathrm{~m}$ (Fig. 8b, c) around $50 \mathrm{~m}$ depth indicate a peak velocity variation between 750 and $550 \mathrm{~m} / \mathrm{s}$, which translates into a $30 \% v_{S}$ reduction across the fault trace. Figure $8 \mathrm{a}-\mathrm{d}$ show that the strongest velocity gradient is also found across $x=0 \mathrm{~m}$ between 20 and $80 \mathrm{~m}$ depth, but shifts to $x=200 \mathrm{~m}$ below $80 \mathrm{~m}$ depth.

This means that the relative velocity variation along $x$ changes with depth (images in right column in Fig. 7a-c). Above $z=80 \mathrm{~m}$, the high-velocity zone constitutes the strongest positive anomaly. Towards greater depth, the low-velocity zone becomes the predominant signal, which is again evident from the $v_{S}$ distributions in Fig. 8a-c $(z<80 \mathrm{~m})$ and Fig. $8 \mathrm{~d}(z>80 \mathrm{~m})$. These images also suggest an increasing velocity reduction at $z>100 \mathrm{~m}$ between the low-velocity zone and the host rock at $x<-200 \mathrm{~m}$ and $x>200 \mathrm{~m}$, even if we consider the weaker constraints indicated by the wider $v_{S}$ distributions at these positions and depths.

Shear wave velocity images obtained from Love wave $U_{L}(x, f)$ data (Fig. $7 \mathrm{~d}-\mathrm{f}$ ) show a strong dependence on the representation. The display of the absolute velocity values in the left column of Fig. 7 accentuate a horizontally layered structure with weak lateral variations. Lateral changes are enhanced in the corresponding scaled images to the right. They exhibit the vertical low-velocity zone seen in the $U_{R^{-}}$ based $v_{S}$ images, but lack an equally prominent highvelocity ridge at small negative distances. The differences in the Rayleigh wave- and Love wavebased images showing absolute $v_{S}$ values in the left column highlight the different, almost complementary, sensitivities (Fig. 10) of vertically and horizontally polarized shear waves along the line. The inferior Love wave data quality-Rayleigh wave results are based on four times as many dataexplains the significantly greater range of $v_{S}$ values for any horizontal or vertical profile (Fig. 8e, f). This is also illustrated by the misfit distribution and the relatively large variability in the synthetic $U_{L}(f)$ curves (Fig. 9b).

Additional evidence of a low-velocity zone to the east of the surface break comes from the shear wave velocity images inverted from Rayleigh wave phase velocity data $c_{R}(x, f)$ (Fig. $\left.7 \mathrm{~g}-\mathrm{i}\right)$. A high-velocity zone to the west of the fault trace is best expressed in the solutions of the linearized inversion (Fig. 7i).

Figures 7 and 8 show that the main $v_{S}$ variation along the line is consistently resolved using all three data sets. The independently obtained $v_{S}$ distributions resolve a 100-200 m wide low-velocity zone, and an adjacent high-velocity body of similar width. The peak $v_{S}$ velocity reduction across the fault trace is $30 \%$. The solutions differ mostly in terms of the absolute shear wave velocity estimates. Around $50 \mathrm{~m}$ depth, average $U_{R^{-}}, U_{L^{-}}$, and $c_{R}$-based estimates are 650,350 , and $1000 \mathrm{~m} / \mathrm{s}$, respectively (Fig. 8). The $U_{R^{-}} U_{L}$ difference can be attributed to the variable sensitivities of the governing $S V$ and $S H$ waves. The 
sensitivity of the average phase velocity estimates to processing choices such as the upper speed limit (Sect. 2.3) can partly explain the discrepancy between the $U_{R^{-}}$and $c_{R}$-based $v_{S}$ levels.

The factor two range in the final 100-200 m width estimate of the low-velocity zone in the top part of the imaged region considers the gradual tapering of the lateral profiles in Fig. $8 \mathrm{a}-\mathrm{c}, \mathrm{e}-\mathrm{h}$ to the east, and the corresponding difficulty of a boundary definition. The spatial correlation length $\Lambda$ (Sect. 2.2) effectively smooths the $U(x, f)$ data along $x$ and implies that the larger bound of this estimation range may better characterize the lowvelocity zone width. Around and below $100 \mathrm{~m}$ depth, the sharp gradients in the $U_{R}$-based $v_{S}$ distributions in Fig. 8d suggest a somewhat better constrained $200 \mathrm{~m}$ width estimate.

\subsection{Focal Spot Properties}

Our findings discussed in Sect. 2.5 demonstrate that the composition of the correlation wavefield varies with frequency, position, and lag time. The $J_{1}$ function shaped RZ and ZR zero-lag amplitude fields suggest a Rayleigh wave dominance at $4 \mathrm{~Hz}$ across the whole array (Fig. 11c, d). Similar conclusions can be drawn for lower frequencies in the area to the east of the fault trace. In contrast, the low-frequency nonzero amplitudes at $r=0 \mathrm{~m}$ observed to the west (Fig. 11e) are not compatible with a refocusing Rayleigh wavefield. As said, the coherency values around unity imply $R$ and $Z$ motion to be in phase, and similarly polarized waves in distant point correlations are also seen to the west of the fault break (Fig. 3d). The velocity structure does affect the relative amplitudes of horizontal and vertical Rayleigh wave motion, but not their phase. Our observations imply thus an intermittent change in the dominant wave type from surface waves to body waves. The location of the observed polarization changes coincides with the position of the highvelocity zone inferred from the dispersion analysis. It is thus likely that the wavefield composition varies as a result from wave interactions with this significant structural feature.

Yet more propagation markers can be extracted from the zero-lag amplitude fields. The zero crossings of $2.5 \mathrm{~Hz} J_{0}$ shaped $\mathrm{ZZ}$ focal spots can be estimated from the $2.5 \mathrm{~Hz}$ Rayleigh wave phase velocities shown in Fig. 6d. These predictions are indicated by the small stubs in Fig. 12a. They agree reasonably well with the observed zero crossing positions, where deviations can be, again, explained by the sensitivity of the $c$-estimates to processing choices. A significant deviation from the overall compatibility, however, is seen in amplitude profiles between reference stations at $x=-150 \mathrm{~m}$ to $x=0 \mathrm{~m}$ and receiver stations to the west of these points (Fig. 12a, d). For these profiles the zero crossing distances are always larger compared to the corresponding profiles to the east, which is evident from the comparison of the black and red lines in Fig. 12a. That is, the $\mathrm{ZZ}$ focal spot asymmetry at $2-3 \mathrm{~Hz}$ (Fig. 12d) occurs in the same area as the longitudinally polarized waves and is thus also collocated with the high-velocity zone to the west of the fault trace.

The RR and TT zero-lag fields of Rayleigh and Love wave motion are parameterized by the sum of $J_{0}$ and $J_{2}$ functions (Haney et al. 2012). In each case the function argument depends only on the associated phase velocity, i.e., on $c_{R}$ and $c_{L}$, respectively. Since both wave types are present in the reconstructed correlation field (Fig. 12b, c), an estimate of the phase velocities from the RR and TT focal spots is not possible. The RR and TT zero-lag fields exhibit a generally higher symmetry at all frequencies (Fig. 12e, f) compared to the $\mathrm{ZZ}$ focal spots. It indicates a more isotropic flux of energy sensed on the horizontal components. The higher asymmetry values at $1-1.5 \mathrm{~Hz}$ and around $x=200 \mathrm{~m}$ are possibly associated with effects of the high-velocity feature and the stronger gradients found in the deeper parts of that area (Figs. 7, 8d).

Together, the 2-3 Hz RZ and ZR zero-lag amplitude shapes, the similarly polarized propagating waves at $1.5-3 \mathrm{~Hz}$, and the $2-3 \mathrm{~Hz} \mathrm{ZZ}$ focal spot asymmetry provide complementary evidence for changes in the wavefield composition to the west of the fault. There remains some ambiguity concerning the relative contribution of surface waves and body waves to the correlation fields on the different components, about the nature of the body waves, and how they affect the observed spatial variations in the polarization pattern. $S$ waves are the assumed 
predominant body wave type, in particular vertically polarized $S$ waves, as they affect the RZ, ZR and ZZ data, but not the RR and TT correlations. We opine that an analysis of three component data from a 2D array would be required to better understand the spatially variable energy flux, wavenumber vectors, and polarization pattern, which all seem affected by the interaction of the wavefield with the high-velocity zone.

\section{Discussion and Conclusions}

The main results of this study are summarized in Fig. 13. The compilation illustrates that the waveforms obtained from the cross-correlation of aftershock seismograms recorded at a dense line array (Fig. 13a) can be used for fault zone imaging. A 2D surface wave tomography based on Rayleigh wave group velocity dispersion in the frequency range 1.8-5.8 Hz (Fig. 13c) yields images of depth dependent, fault-normal shear wave velocity variations (Fig. 13d, e). In the top $80 \mathrm{~m}$ the $v_{S}(x, z)$ patterns are dominated by a 100-200 m wide lowvelocity zone to the east of the surface break, and by a high-velocity zone of similar lateral extent to the west of the break. The position and width of these two main features is supported by consistent $v_{S}(x, z)$ images based on inversions of Love wave group velocity and Rayleigh wave phase velocity data (Fig. 6c-g).

The low-velocity zone continues towards greater depths, whereas the signature of the high-velocity anomaly appears restricted to the shallow parts without breaking the surface. An additional consequence of the high-velocity zone is the reduced Rayleigh wave ray path coverage in this area, in particular at frequencies below $3 \mathrm{~Hz}$ (hit count, Fig. 6a, b, d). This suggests the feature deflects or scatters waves, and the surface wave data containing the interfering body wave energy are mostly winnowed by the quality control. Also coincident with the high-velocity zone are low-frequency longitudinally polarized propagating waves, zero-lag RZ and ZR focal spot values that are incompatible with Rayleigh wave refocusing, and asymmetric $\mathrm{ZZ}$ focal spots. We think that all phenomena result from wavefield interactions with the high-velocity zone (Figs. 12d, 13c, d).

On the other hand, wavefronts arriving after the direct surface wave are signatures of propagation in the low-velocity zone. These later arrivals emerge predominantly in correlations associated with reference stations located on top of the low-velocity zone between $x=-50 \mathrm{~m}$ and $x=200 \mathrm{~m}$. Their longitudinal and elliptical motions (Fig. 3d, g) indicate reflected body wave and surface wave energy, respectively. The arrival time and polarization varies with frequency and position of the correlation reference station. Some of these arrivals can be traced across an apparent criss-crossing pattern out to $4 \mathrm{~s}$ in the coda (Fig. 3f), suggesting that this energy is reflected inside or reverberates within the low-velocity waveguide (Fig. 13b; Hillers and Campillo 2016).

A formal uncertainty assessment of the dispersion maps and shear wave velocity images would include the effects of the many, often nonlinear, steps during data acquisition, processing, and inversion. Modern approaches considering the uncertainties in the data and the model space (e.g., Bodin et al. 2012) can be adopted to construct probability maps of the position and amplitude of the velocity gradient, or the width and velocity reduction of the low-velocity zone. In a similar manner, the density distributions compiled from the many velocity models obtained with the neighborhood algorithm (Figs. 8, 9) indicate how well the solutions are constrained by the data at a given position. These maps and the sensitivity kernels from the linearized inversion (Fig. 10) show that the Rayleigh wave group velocity data best constrain the shear wave velocity models. Our estimates of the position and width of the low-velocity and the adjacent high-velocity zones, and the peak velocity reduction, are hence well resolved. Significant uncertainties concern only the velocities in the halfspace in the poorly sampled margin areas.

The sensitivity of the obtained velocity distributions can also be probed by varying key tuning parameters. That is, an alternative quality marker is the consistency between $v_{S}$ images obtained with different data (sub)sets. Neglecting any of the ZZ, RR, RZ, and ZR data in the Rayleigh wave group velocity analysis; considering time-symmetric 


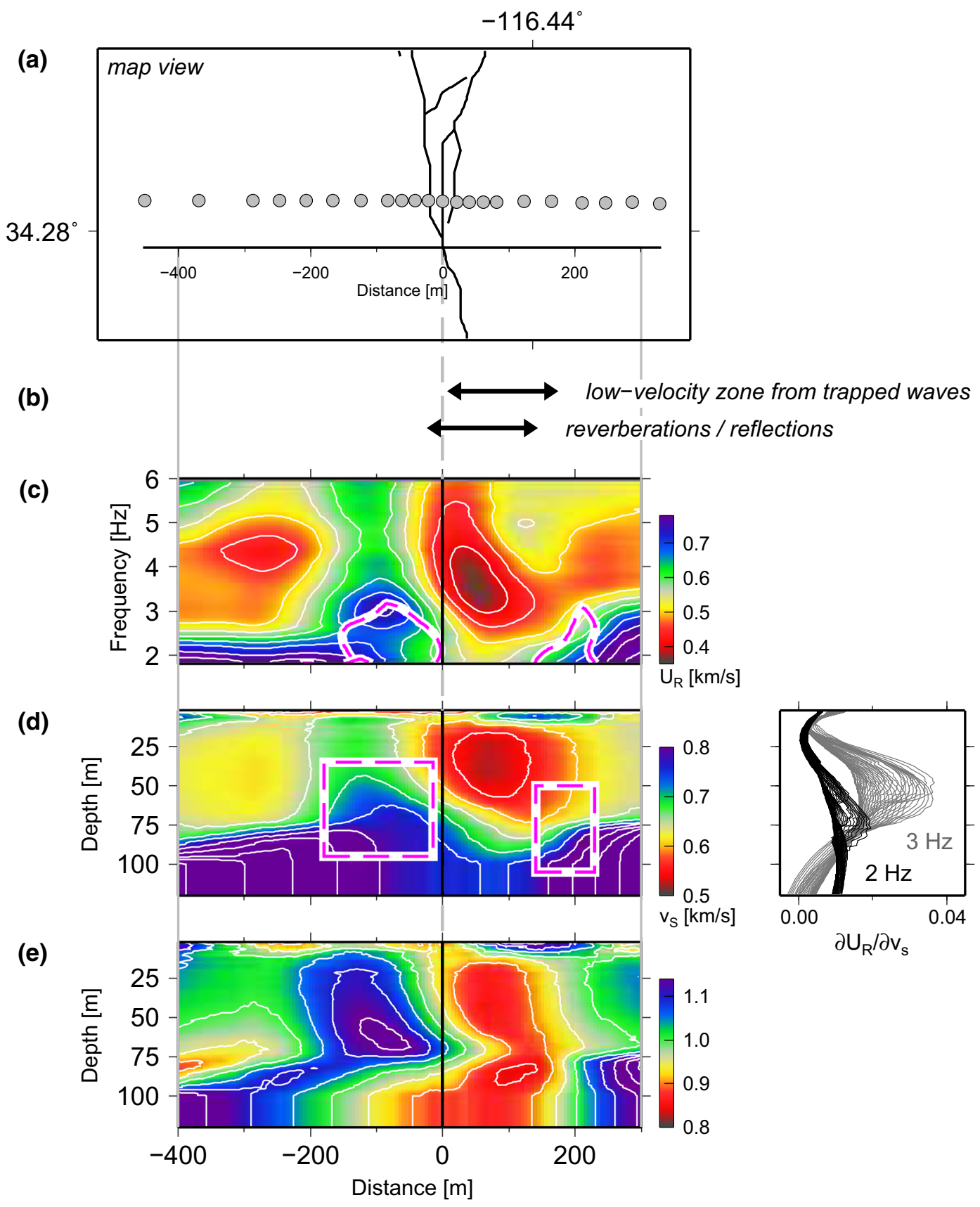

Figure 13

Summary of the main results. a Map view of the fault surface break (black lines) and geometry of the line array (circles). b The upper arrow indicates the position and extension of the low-velocity zone estimated from fault zone trapped waves (Li et al. 1994a, b; Peng et al. 2003). The lower arrow indicates the range where signatures of fault zone reverberations or reflections emerge (Fig. 3a, c, e-g). c Rayleigh wave group velocity dispersion $U_{R}(x, f)$, from Fig. 6a. The magenta-and-white contours indicate the range for which the ZZ and RR focal spots are asymmetric (see Fig. 12d, e). d Shear velocity distribution from 50 best models obtained with the neighborhood algorithm (similar to Fig. 7a, b). The magenta-and-white boxes correspond to the contours in $\mathbf{c}$ considering the sensitivity kernels in these along-line segments to the right. 
functions or data from negative and/or positive lag times; and changing filtering, data winnowing, and averaging parameters within reasonable bounds produces results that are all very similar to our preferred solution (Figs. 7a-c, 13d, e). The resulting velocity distributions differ mostly in the amplitude of the velocity variations, but the key properties-the location and width-of the high- and low-velocity zones are notably robust. Similar conclusions apply to $v_{S}$ images based on inverted Rayleigh wave phase velocity data, which are generally compatible with the group velocity results.

A stack of correlations from 50-100 events yields sufficiently converged Green's function estimates (Fig. 2c). This conclusion is based on the evolution of the similarity to the final stack, and considers the overall small gain in signal after stacking about 100 events. The small gain refers to the decreasing slope in the square-root-type functions (Larose et al. 2007). Convergence varies with inter-station distance and component pair. It is fastest for small station offsets and same-component correlations. Stacked waveforms obtained from database subsets selected by spatial criteria (events to the north or to the south of the array) tend to be more dissimilar to each other compared to seismogram pairs associated with subsets based on timing (order of occurrence). This highlights the advantage of a more isotropic hypocenter distribution. Hence we think that the persistent asymmetry in the converged stacks (Figs. 2a, 3) is caused by the inhomogeneous event distribution with most events located to the north of the array (Fig. 1). Anisotropic source or flux directions can be mitigated using computationally expensive window-optimization schemes (Chaput et al. 2016) or azimuthal normalization techniques (Seydoux et al. 2015) that rely, however, on 2D array geometries.

The azimuthal aftershock distribution associated with straight segments of mature fault zones such as the Parkfield section of the San Andreas fault may be more limited compared to the present data set (Allmann and Shearer 2007). This can bias the arrival times in the reconstructed Green's functions along fault-normal line arrays and hence influence the obtained images. However, scattering in the crust tends to randomize the propagation directions in the earthquake wavefields, and this positive effect can be further enhanced by focusing on later parts of the coda (Gouédard et al. 2008).

In comparison to the here required stacking of some 100 events, Hillers and Campillo (2016) obtained converged stacks of correlations from just 25 regional earthquake seismograms from a similar line array across the Calico fault that is located some $10 \mathrm{~km}$ to the east of the Landers earthquake fault. However, the magnitude 3-4.6 range and the longer records available for that study allowed the correlation of up to $5 \mathrm{~min}$ long earthquake waveforms. The total length of the correlated data hence exceeds the here used signals by a factor of three. The good convergence of the fewer late-coda correlations in Hillers and Campillo (2016) indicates that more diffuse wavefields generally lead to better Green's function estimates (Paul et al. 2005). By reconstructing fault zone reverberations from correlations of both ambient noise and earthquake seismograms, Hillers and Campillo (2016) demonstrated that these fault zone signatures are indeed part of the seismic Green's function. By analogy we infer that the here shown in-fault reflections and reverberations are not spurious or governed by the inhomogeneous event distribution, but are manifestations of the strong velocity contrasts in the faulting environment.

We highlight the independence of the approach on information about the aftershock source parameters. Hypocenter locations are useful to understand general flux patterns, but travel time differences of direct waves across the array are irrelevant for our analysis and interpretation. In contrast, accurate estimates of source locations are essential for studying fault zone waves as a function of source and waveguide geometry, and for the uncertainty reduction in earthquake tomography. The independence on knowledge of source parameters can constitute a practical advantage. Considering temporary network deployments for aftershock recordings of moderate to large crustal earthquakes, the method can deliver images by processing the first few hundred earthquake waveforms quickly - again independent on information that require more elaborate processing (event size and location)—using the here employed stringing of the standard techniques correlation, dispersion analysis, and surface wave velocity inversion. 
This can guide network updates for optimal coverage of interesting geological features such as the here studied fault zone architecture, or the imaging of the spatial velocity distribution in areas of strongly variable ground shaking.

The analysis of fault zone head waves and trapped waves yields images of boundaries and interfaces with a potential resolution of tens of meters. The here adopted procedure is complementary to these approaches by providing independent estimates on the local fault zone characteristics such as velocity contrast and waveguide width. The high resolution of fault zone wave analysis may not be met considering the damping and smoothing in the lateral 1D inversions of the dispersion data that is necessary to trade off model roughness and misfit. However, independent observations of the fine structure can better constrain the strong non-uniqueness in trapped waves-based estimates of waveguide width, velocity, earthquake source location, propagation distance inside the waveguide, and the quality factor $Q$ (BenZion 1998; Peng et al. 2003; Haberland et al. 2003). Attenuation properties can also be estimated from scattered wavefield correlations (Cupillard and Capdeville 2010; Prieto et al. 2011; Weaver 2013; Liu et al. 2015), and can thus also help constrain the trade-off in trapped waves inversions.

The approximately orthogonal trajectories of the fault-normal propagating surface waves and the along-fault propagating trapped waves have different sensitivities and resolution power. Trapped waves excitation is sensitive to the hypocenter location relative to the trapping structure, and the waveforms reflect average waveguide properties along the propagation path. Trapped waves excited in different source regions and at different depths can constrain direction dependent waveguide properties (Peng et al. 2003). The obtained path-average properties can potentially differ from the local velocity structure beneath the array inferred from the surface wave analysis.

Tomographic methods applied to dense network data in faulting environments can better resolve nontrapping, but mechanically similarly important highvelocity regions (Rempe et al. 2013; Roux et al. 2016; Hillers et al. 2016). The obtained images can thus be more complex compared to the layer- between-two-quarter-spaces model that is commonly used in trapped waves inversions (Ben-Zion 1998). Compared to the high-frequency surface wave approach, however, trapped waves offer a better resolution of the trapping structure at depth, again, by analyzing the configuration of waveguide model and earthquake source.

The quality and implications of our results can be assessed by comparing them to previous observations of the Landers fault structure based on the same data set. Analyzing trapped wave trains and body wave move out patterns at central frequencies of 3.5, 4.5, 4, and $8 \mathrm{~Hz}$, Li et al. (1994a, b, 2007) and Peng et al. (2003) found a low-velocity zone with a thickness of 180, 100-200, 200, and 270-360 m, respectively. The latter three of these works estimate the velocity reduction to $30-50,30-40$, and 35-60\%. These numbers agree well with our 100-200 m width and 30-50\% reduction estimates. The consistency includes further the location of the low-velocity zone to the east of the surface break (Fig. 13b), corroborating the asymmetric structure with respect to the mapped fault.

Our high-frequency surface wave analysis could not have contributed to the controversy concerning the vertical extension of the waveguide ( $\mathrm{Li}$ et al. 1994a; Peng et al. 2003). It seems now commonly accepted that strike-slip fault low-velocity zones do not continue to the base of the seismogenic zone, but extend to one to five kilometers depth. The coherent arrivals at later lapse times, i.e., in the coda of the cross-correlation functions (Fig. 3c, g), can inform about strong vertical velocity gradients associated with the low-velocity zone and thus of its limit at depth (Draganov et al. 2007). The emergence of multiples supports the interpretation that the lowvelocity zone acts as a waveguide. These reflections constitute useful target signals in a modern full waveform inversion for improved fault zone imaging.

The upward "fingering" intrusion-like character of the high-velocity region in our $v_{S}(x, z)$ images is compatible with observations along the Carboneras, San Andreas, and San Jacinto fault zones (Jones et al. 2010; Rempe et al. 2013; Roux et al. 2016) including the observation that they do not break the surface. Low-velocity zones usually correlate with mapped strands of fault gouge, indicating less competent, 
compliant material that is also characterized by stronger attenuation. However, bodies of increased velocities correlate with damaged materials too, which highlights that seismic velocities in fault zone environments are non-unique functions of damage, anisotropy, and microstructure (Rempe et al. 2013). Regions characterized by increased seismic velocities have been described in areas of enhanced structural complexity, where faults splay, which is consistent with the branching of the mapped surface break at the array location in Fig. 13a.

We demonstrated that the waveforms obtained from the cross-correlation of $15 \mathrm{~s}$ long records of scattered high-frequency earthquake wavefields constitute an important resource for imaging. The reconstruction of high-frequency Rayleigh waves, Love waves, focal spots, and multiples from stacks of aftershock waveform correlations shows that earthquake seismograms can contribute to fault zone imaging even if they do not contain clean signatures of head waves, trapped waves, or reflected body waves. Rough arrival time estimates are sufficient for the selection and processing of high-energy transients which makes the approach interesting for imaging during aftershock campaigns of medium to large crustal earthquakes. Considering the increasing number of portable, autonomous sensors available for such campaigns, aftershock correlations can provide high resolution images quickly, and can thus inform potential network reconfigurations after the collection of some few hundred events. More generally, the correlation of background seismicity data collected by sufficiently dense deployments can potentially become a widespread extension of the ambient field correlation approach for improved high-frequency surface wave imaging.

\section{Acknowledgements}

We thank Z. Peng for help with the database and M. Wathelet, A. Mordret, and D. Faulkner for discussions. We thank the Editor B. Edwards, reviewer P.-E. Share, and an anonymous reviewer for comments that helped to improve the manuscript. G. Hillers acknowledges support through a Heisenberg fellowship from the German Research Foundation (HI 1714/1-2).
M. Campillo acknowledges support from Institut Universitaire de France. This project has received funding from the European Research Council (ERC) under the European Union's Horizon 2020 research and innovation program (grant Agreement No. 742335, F-IMAGE). Most figures are made using the Generic Mapping Tools (Wessel and Smith 1998).

\section{REFERENCES}

Aki, K. (1957). Space and time spectra of stationary stochastic waves, with special reference to microtremors. Bulletin of the Earthquake Research Institute, The University of Tokyo, 35, 415-457.

Allam, A. A., \& Ben-Zion, Y. (2012). Seismic velocity structures in the Southern California plate-boundary environment from double-difference tomography. Geophysical Journal International, 190, 1181-1196. https://doi.org/10.1111/j.1365-246X. 2012.05544.x.

Allam, A. A., Ben-Zion, Y., \& Peng, Z. (2014). Seismic imaging of a bimaterial interface along the Hayward Fault, CA, with fault zone head waves and direct P arrivals. Pure and Applied Geophysics, 171, 2993-3011. https://doi.org/10.1007/s00024-014-0784-0.

Allmann, B. P., \& Shearer, P. M. (2007). Spatial and temporal stress drop variations in small earthquakes near Parkfield, California. Journal of Geophysical Research, 112, B04305. https:// doi.org/10.1029/2006JB004395.

Andrews, D. J., \& Ben-Zion, Y. (1997). Wrinkle-like slip pulse on a fault between different materials. Journal of Geophysical Research, 102(B1), 553-571.

Asten, M. W. (2006). On bias and noise in passive seismic data from finite circular array data processed using SPAC methods. Geophysics, 71(6), V153-V162. https://doi.org/10.1190/1. 2345054.

Ben-Zion, Y. (1998). Properties of seismic fault zone waves and their utility for imaging low-velocity structure. Journal of Geophysical Research, 103(B6), 12,567-12,585.

Ben-Zion, Y., \& Aki, K. (1990). Seismic radiation from an SH line source in a laterally heterogeneous planar fault zone. Bulletin of the Seismological Society of America, 80(4), 971-994.

Ben-Zion, Y., Katz, S., \& Leary, P. (1992). Joint inversion of fault zone head waves and direct $\mathrm{P}$ arrivals for crustal structure near major faults. Journal of Geophysical Research, 97, 1943-1951.

Ben-Zion, Y., Vernon, F. L., Ozakin, Y., Zigone, D., Ross, Z. E., Meng, H., et al. (2015). Basic data features and results from a spatially-dense seismic array on the San Jacinto fault zone. Geophysical Journal International, 202, 370-380. https://doi. org/10.1093/gji/ggv14.

Benech, N., Catheline, S., Brum, J., Gallot, T., \& Negreira, C. A. (2009). 1-D elasticity assessment in soft solids from shear wave correlation: The time-reversal approach. IEEE Transactions on Ultrasonics, Ferroelectrics, and Frequency Control, 56(11), 2400-2410.

Bodin, T., Sambridge, M., Tkalcic, H., Arroucau, P., Gallagher, K., \& Rawlinson, N. (2012). Transdimensional inversion of receiver functions and surface wave dispersion. Journal of Geophysical Research, 117, B02301. https://doi.org/10.1029/2011JB008560. 
Campillo, M., \& Paul, A. (2003). Long-range correlations in the diffuse seismic coda. Science. https://doi.org/10.1126/science. 1078551.

Campillo, M., \& Roux, P. (2015). Crust and lithospheric structureseismic imaging and monitoring with ambient noise correlations. In G. Schubert (Ed.), Treatise on geophysics (Vol. 1, pp. 391-417). Oxford: Elsevier.

Campillo, M., Singh, S. K., Shapiro, N., Pacheco, J., \& Herrmann, R. B. (1996). Crustal structure south of the Mexican volcanic belt, based on group velocity dispersion. Geofísica Internacional, 35, 361-370.

Catheline, S., Benech, N., Brum, J., \& Negreira, C. (2008). Time reversal of elastic waves in soft solids. Physical Review Letters, 100(6), 064301. https://doi.org/10.1103/PhysRevLett.100. 064301.

Chaput, J., Campillo, M., Aster, R. C., Roux, P., Kyle, P. R., Knox, H., et al. (2015). Multiple scattering from icequakes at Erebus volcano, Antarctica; Implications for imaging at glaciated volcanoes. Journal of Geophysical Research, 120, 1129-1141. https://doi.org/10.1002/2014JB011278.

Chaput, J., Clerc, V., Campillo, M., Roux, P., \& Knox, H. (2016). On the practical convergence of coda-based correlations: A window optimization approach. Geophysical Journal International, 204(2), 736-747. https://doi.org/10.1093/gji/ggv476.

Cupillard, P., \& Capdeville, Y. (2010). On the amplitude of surface waves obtained by noise correlation and the capability to recover the attenuation: A numerical approach. Geophysical Journal International, 181, 1687-1700. https://doi.org/10.1111/j.1365246X.2010.04568.x.

Draganov, D., Wapenaar, K., Mulder, W., Singer, J., \& Verdel, A. (2007). Retrieval of reflections from seismic background-noise measurements. Geophysical Research Letters, 34, L04305. https://doi.org/10.1029/2006GL028735.

Fang, H., Zhang, H., Yao, H., Allam, A., Zigone, D., \& Ben-Zion, Y., et al. (2016). A new algorithm for three-dimensional joint inversion of body wave and surface wave data and its application to the Southern California plate boundary region. Journal of Geophysical Research: Solid Earth. https://doi.org/10.1002/ 2015JB012702.

Fink, M., Prada, C., Wu, F., \& Cassereau, D. (1989). Self-focusing in inhomogeneous media with time-reversal acoustic mirrors. Proceedings IEEE Ultrasonics Symposium, 2, 681-686.

Gabriel, A. A., Ampuero, J. P., Dalguer, L. A., \& Mai, P. M. (2013). Source properties of dynamic rupture pulses with offfault plasticity. Journal of Geophysical Research, 118, 4117-4126. https://doi.org/10.1002/jgrb.50213.

Gallot, T., Catheline, S., Roux, P., Brum, J., Benech, N., \& Negreira, C. (2011). Passive elastography: Shear-wave tomography from physiological-noise correlation in soft tissues. IEEE Transactions on Ultrasonics, Ferroelectrics, and Frequency Control, 58(6), 1122-1126.

Gouédard, P., Roux, P., Campillo, M., \& Verdel, A. (2008). Convergence of the two-point correlation function toward the Green's function in the context of a seismic-prospecting data set. Geophysics, 73(6), 47-53. https://doi.org/10.1190/1.2985822.

Haberland, C., Agnon, A., El-Kelani, R., Maercklin, N., Qabbani, I., \& Rümpker, R., et al. (2003). Modeling of seismic guided waves at the Dead Sea Transform. Journal of Geophysical Research. https://doi.org/10.1029/2002JB002309.

Haney, M. M., Mikesell, T. D., van Wijk, K., \& Nakahara, H. (2012). Extension of the spatial autocorrelation (SPAC) method to mixed-component correlations of surface waves. Geophysical Journal International, 192, 189-206. https://doi.org/10.1111/j. 1365-246X.2012.05597.x.

Hansen, P. C. (1992). Analysis of discrete ill-posed problems by means of the L-curve. SIAM Review, 34(4), 561-580.

Hauksson, E., Jones, L. M., Hutton, K., \& Eberhart-Phillips, D. (1993). The 1992 Landers earthquake sequence: Seismological observations. Journal of Geophysical Research, 98(B11), $19,835-19,858$

Herrmann, R. B. (2006). Computer programs in seismology, vers. 3.30; An overview of synthetic seismogram computation. Tech. rep., Saint Louis University. http://www.eas.slu.edu/People/ RBHerrmann/ComputerPrograms.html

Hillers, G., \& Campillo, M. (2016). Fault zone reverberations from cross-correlations of earthquake waveforms and seismic noise. Geophysical Journal International, 204(3), 1503-1517. https:// doi.org/10.1093/gji/ggv515.

Hillers, G., Campillo, M., Ben-Zion, Y., \& Roux, P. (2014). Seismic fault zone trapped noise. Journal of Geophysical Research, 119(7), 5786-5799. https://doi.org/10.1002/ 2014JB011217.

Hillers, G., Roux, P., Campillo, M., \& Ben-Zion, Y. (2016). Focal spot imaging based on zero lag cross correlation amplitude fields: Application to dense array data at the San Jacinto fault zone. Journal of Geophysical Research: Solid Earth. https://doi.org/10. 1002/2016JB013014.

Hong, T. K., \& Menke, W. (2006). Tomographic investigation of the wear along the San Jacinto fault, Southern California. Physics of the Earth and Planetary Interiors, 155, 236-248.

Igel, H., Ben-Zion, Y., \& Leary, P. C. (1997). Simulation of SHand P-SV-wave propagation in fault zones. Geophysical Journal International, 128, 533-546.

Jones, C., Nippress, S., Rietbrock, A., Faulkner, D. R., Rutter, E. H., Haberland, C. A., \& Teixido, T. (2010). The shallow velocity structure of the Carboneras fault zone from high-resolution seismic investigations. AGU Fall Meeting Abstracts. Abstract T41B-2111

Kurzon, I., Vernon, F. L., Ben-Zion, Y., \& Atkinson, G. (2014). Ground motion prediction equations in the San Jacinto fault zone-significant effects of rupture directivity and fault zone amplification. Pure and Applied Geophysics. https://doi.org/10. 1007/s00024-014-0855-2.

Larose, E., Roux, P., \& Campillo, M. (2007). Reconstruction of Rayleigh-Lamb dispersion spectrum based on noise obtained from an air-jet forcing. Journal of the Acoustical Society of America, 122(6), 3437-3444. https://doi.org/10.1121/1.2799913.

Li, H., Zhu, L., \& Yang, H. (2007). High-resolution structures of the Landers fault zone inferred from aftershock waveform data. Geophysical Journal International, 171, 1295-1307. https://doi. org/10.1111/j.1365-246X.2007.03608.x.

Li, Y. G., Leary, P., Aki, K., \& Malin, P. (1990). Seismic trapped modes in the Oroville and San Andreas fault zones. Science, 249(4970), 763-766. https://doi.org/10.1126/science.249.4970. 763.

Li, Y. G., Aki, K., Adams, D., Hasemi, A., \& Lee, W. H. K. (1994a) Seismic guided waves trapped in the fault zone of the Landers, California, earthquake of 1992. Journal of Geophysical Research, 99(B6):11,705-11,722

Li, Y. G., Vidale, J., Aki, K., Marone, C. J., \& Lee, W. H. K. (1994b). Fine structure of the Landers fault zone: Segmentation and the rupture process. Science, 265, 367-370. 
Lin, F. C., \& Ritzwoller, M. H. (2011). Helmholtz surface wave tomography for isotropic and azimuthally anisotropic structure. Geophysical Journal International, 186, 1104-1120. https://doi. org/10.1111/j.1365-246X.2011.05070.x.

Lin, F. C., Ritzwoller, M. H., \& Snieder, R. (2009). Eikonal tomography: Surface wave tomography by phase front tracking across a regional broad-band seismic array. Geophysical Journal International, 177, 1091-1110. https://doi.org/10.1111/j.1365246X.2009.04105.x.

Lin, F. C., Li, D., Clayton, R. W., \& Hollis, D. (2013). Highresolution 3D shallow crustal structure in Long Beach, California: Application of ambient noise tomography on a dense seismic array. Geophysics, 78(4), Q45-Q56. https://doi.org/10.1190/ GEO2012-0453.1.

Liu, X., Ben-Zion, Y., \& Zigone, D. (2015). Extracting seismic attenuation coefficients from cross-correlations of ambient noise at linear triplets of stations. Geophysical Journal International, 203, 1149-1163. https://doi.org/10.1093/gji/ggv357.

Ma, S., \& Andrews, D. J. (2010). Inelastic off-fault response and three-dimensional dynamics of earthquake rupture on a strikeslip fault. Journal of Geophysical Research, 115, B04304. https://doi.org/10.1029/2009JB006382.

McGuire, J., \& Ben-Zion, Y. (2005). High-resolution imaging of the Bear Valley section of the San Andreas Fault at seismogenic depths with fault-zone head waves and relocated seismicity. Geophysical Journal International, 163, 152-164. https://doi. org/10.1111/j.1365-246X.2005.02703.x.

Mordret, A., Shapiro, N. M., Singh, S. S., Roux, P., \& Barkved, O. I. (2013). Helmholtz tomography of ambient noise surface wave data to estimate Scholte wave phase velocity at Valhall Life of the Field. Geophysics, 78(2), WA99-WA109. https://doi.org/10. 1190/GEO2012-0303.1.

Nakata, N., Chang, J. P., Lawrence, J. F., \& Boué, P. (2015). Body wave extraction and tomography at Long Beach, California, with ambient-noise interferometry. Journal of Geophysical Research, 120, 1159-1173. https://doi.org/10.1002/2015JB011870.

Ozakin, Y., Ben-Zion, Y., Aktar, M., Karabulut, H., \& Peng, Z. (2012). Velocity contrast across the 1944 rupture zone of the North Anatolian fault east of Ismetpasa from analysis of teleseismic arrivals. Geophysical Research Letters, 39, L08307. https://doi.org/10.1029/2012GL051426.

Paul, A., Campillo, M., Margerin, L., Larose, E., \& Derode, A. (2005). Empirical synthesis of time-asymmetrical Green function from the correlation of coda waves. Journal of Geophysical Research, 110, B08302. https://doi.org/10.1029/2004JB003521.

Peng, Z., Ben-Zion, Y., Michael, A. J., \& Zhu, L. (2003). Quantitative analysis of seismic fault zone waves in the rupture zone of the 1992 Landers, California, earthquake: Evidence for a shallow trapping structure. Geophysical Journal International, 155, 1021-1041.

Prieto, G. A., Denolle, M., Lawrence, J. F., \& Beroza, G. C. (2011). On amplitude information carried by the ambient seismic field. Comptes Rendus Geoscience, 343, 600-614. https://doi.org/10. 1016/j.crte.2011.03.001.

Rempe, M., Mitchell, T., Renner, J., Nippress, S., Ben-Zion, Y., \& Rockwell, T. (2013). Damage and seismic velocity structure of pulverized rocks near the San Andreas Fault. Journal of Geophysical Research, 118, 2813-2831. https://doi.org/10.1002/jgrb. 50184.

Roten, D., Olsen, K. B., Day, S. M., Cui, Y., \& Fäh, D. (2014). Expected seismic shaking in Los Angeles reduced by San
Andreas fault zone plasticity. Geophysical Research Letters, 41, 2769-2777. https://doi.org/10.1002/2014GL059411.

Roux, P. (2009). Passive seismic imaging with direct ambient noise: Application to surface waves and the San Andreas Fault in Parkfield, CA. Geophysical Journal International, 179, 367-373. https://doi.org/10.1111/j.1365-246X.2009.04282.x.

Roux, P., \& Ben-Zion, Y. (2014). Monitoring fault zone environments with correlations of earthquake waveforms. Geophysical Journal International, 196, 1073-1081. https://doi.org/10.1093/ gji/ggt441.

Roux, P., Moreau, L., Lecointre, A., Hillers, G., Campillo, M., Ben-Zion, Y., et al. (2016). A methodological approach towards high-resolution seismic imaging of the San Jacinto Fault Zone using ambient-noise recordings at a spatially dense array. Geophysical Journal International, 206, 980-992. https://doi.org/10. 1093/gji/ggw193.

Sambridge, M. (1999). Geophysical inversion with a neighbourhood algorithm-I. Searching a parameter space. Geophysical Journal International, 138, 479-494.

Seydoux, L., Shapiro, N., de Rosny, J., \& Landès, M. (2015). A spatial coherence analysis of seismic wavefields based on array covariance matrix: Application to one year of USArray data. Eos Trans AGU Fall Meet. Suppl., Abstract S34B-04

Tape, C., Liu, Q., Maggi, A., \& Tromp, J. (2009). Adjoint tomography of the Southern California crust. Science, 325, 988-992. https://doi.org/10.1126/science.1175298.

Tarantola, A., \& Valette, B. (1982). Generalized nonlinear inverse problems solved using the least squares criterion. Reviews of Geophysics, 20(2), 219-232.

Thurber, C., Zhang, H., Waldhauser, F., Hardebeck, J., Michael, A., \& Eberhart-Phillips, D. (2006). Three-dimensional compressional wavespeed model, earthquake relocations, and focal mechanisms for the Parkfield, California. Region Bulletin of the Seismological Society of America, 96(4B), S38-S49.

Wald, D. J., \& Heaton, T. H. (1994). Spatial and temporal distribution of slip for the 1992 Landers, California, earthquake. Bulletin of the Seismological Society of America, 84(3), 668-691.

Wathelet, M. (2008). An improved neighborhood algorithm: Parameter conditions and dynamic scaling. Geophysical Research Letters, 35, L09301. https://doi.org/10.1029/ 2008 GL033256.

Wathelet, M., Jongmans, D., \& Ohrnberger, M. (2004). Surfacewave inversion using a direct search algorithm and its application to ambient vibration measurements. Near Surface Geophysics, 2 , 211-221.

Weaver, R. L. (2013). On the retrieval of attenuation and site amplification from ambient noise on linear arrays: Further numerical simulations. Geophysical Journal International, 193, 1644-1657. https://doi.org/10.1093/gji/ggt063.

Wessel, P., \& Smith, W. H. F. (1998). New, improved version of generic mapping tools released. Eos Trans AGU. https://doi.org/ 10.1029/98EO00426.

Yang, H., \& Zhu, L. (2010). Shallow low-velocity zone of the San Jacinto fault from local earthquake waveform modeling. Geophysical Journal International, 183, 421-432. https://doi.org/10. 1111/j.1365-246X.2010.04744.x.

Yang, H., Zhu, L., \& Cochran, E. S. (2011). Seismic structures of the Calico fault zone inferred from local earthquake travel time modelling. Geophysical Journal International, 186, 760-770. https://doi.org/10.1111/j.1365-246X.2011.05055.x. 
Yang, H., Li, Z., Peng, Z., Ben-Zion, Y., \& Vernon, F. (2014). Low-velocity zones along the San Jacinto fault, Southern California, from body waves recorded in dense linear arrays. Journal of Geophysical Research: Solid Earth, 119, 8976-8990. https:// doi.org/10.1002/2014JB011548.
Zigone, D., Ben-Zion, Y., Campillo, M., \& Roux, P. (2015). Seismic tomography of the Southern California plate boundary region from noise-based Rayleigh and Love Waves. Pure and Applied Geophysics, 172, 1007-1032. https://doi.org/10.1007/ s00024-014-0872-1.

(Received June 13, 2017, revised March 5, 2018, accepted March 9, 2018) 